\title{
Observation of absorbing aerosols above clouds over the south-east Atlantic Ocean from the geostationary satellite SEVIRI - Part 1: Method description and sensitivity
}

\author{
Fanny Peers ${ }^{1}$, Peter Francis ${ }^{2}$, Cathryn Fox ${ }^{2}$, Steven J. Abel ${ }^{2}$, Kate Szpek ${ }^{2}$, Michael I. Cotterell ${ }^{1,2}$, \\ Nicholas W. Davies ${ }^{1,2}$, Justin M. Langridge ${ }^{2}$, Kerry G. Meyer ${ }^{3}$, Steven E. Platnick ${ }^{3}$, and Jim M. Haywood ${ }^{1,2}$ \\ ${ }^{1}$ College of Engineering, Mathematics, and Physical Sciences, University of Exeter, Exeter, UK \\ ${ }^{2}$ Met Office, Fitzroy Road, Exeter, UK \\ ${ }^{3}$ NASA Goddard Space Flight Center, Greenbelt, Maryland, USA
}

Correspondence: Fanny Peers (f.peers@ exeter.ac.uk)

Received: 21 December 2018 - Discussion started: 10 January 2019

Revised: 10 May 2019 - Accepted: 19 June 2019 - Published: 31 July 2019

\begin{abstract}
High-temporal-resolution observations from satellites have a great potential for studying the impact of biomass burning aerosols and clouds over the south-east Atlantic Ocean (SEAO). This paper presents a method developed to simultaneously retrieve aerosol and cloud properties in aerosol above-cloud conditions from the geostationary instrument Meteosat Second Generation/Spinning Enhanced Visible and Infrared Imager (MSG/SEVIRI). The abovecloud aerosol optical thickness (AOT), the cloud optical thickness (COT) and the cloud droplet effective radius (CER) are derived from the spectral contrast and the magnitude of the signal measured in three channels in the visible to shortwave infrared region. The impact of the absorption from atmospheric gases on the satellite signal is corrected by applying transmittances calculated using the water vapour profiles from a Met Office forecast model. The sensitivity analysis shows that a $10 \%$ error on the humidity profile leads to an $18.5 \%$ bias on the above-cloud AOT, which highlights the importance of an accurate atmospheric correction scheme. In situ measurements from the CLARIFY-2017 airborne field campaign are used to constrain the aerosol size distribution and refractive index that is assumed for the aforementioned retrieval algorithm. The sensitivities in the retrieved AOT, COT and CER to the aerosol model assumptions are assessed. Between 09:00 and 15:00 UTC, an uncertainty of $40 \%$ is estimated on the above-cloud AOT, which is dominated by the sensitivity of the retrieval to the single-scattering albedo. The absorption AOT is less sensitive to the aerosol assumptions with an uncertainty generally lower than $17 \%$
\end{abstract}

between 09:00 and 15:00 UTC. Outside of that time range, as the scattering angle decreases, the sensitivity of the AOT and the absorption AOT to the aerosol model increases. The retrieved cloud properties are only weakly sensitive to the aerosol model assumptions throughout the day, with biases lower than $6 \%$ on the COT and $3 \%$ on the CER. The stability of the retrieval over time is analysed. For observations outside of the backscattering glory region, the time series of the aerosol and cloud properties are physically consistent, which confirms the ability of the retrieval to monitor the temporal evolution of aerosol above-cloud events over the SEAO.

\section{Introduction}

The south-east Atlantic Ocean (SEAO) provides a natural laboratory for analysing the full range of aerosol-cloudradiation interactions. During the fire season, large amounts of particles from African biomass burning are transported above the semi-permanent deck of stratocumulus covering this oceanic region. As a result, an important contrast is expected in the direct radiative effect (DRE) of aerosols (i.e. the direct impact of aerosol scattering and absorption of radiation). On the one hand, the aerosol scattering above the ocean typically increases the local albedo, which leads to a negative DRE at the top of the atmosphere. On the other hand, the sign of the DRE above clouds depends on the underlying cloud albedo and the aerosol absorption. Positive instantaneous DRE of up to $+130 \mathrm{~W} \mathrm{~m}^{-2}$ has been observed by 
satellite instruments over the SEAO (De Graaf et al., 2012; Peers et al., 2015). There are many poorly constrained variables, such as the aerosol and cloud properties and vertical structure of aerosol and clouds (Peers et al., 2016), which result in a large spread in the DRE derived from climate models in this region (Zuidema et al., 2016). In addition, the absorption of radiation by aerosols leads to a modification of the atmospheric stability and consequently of the formation, development and dissipation of clouds, i.e. semidirect effect. Studies have shown that the overlying African biomass burning aerosols are associated with a cloud thickening (Wilcox, 2010, 2012). This negative semi-direct effect partly compensates for the positive DRE of aerosols above clouds over the SEAO. However, as an aerosol plume moves away from the coast and descends into the boundary layer, the heat due to the aerosol absorption could lead to a reduction of the cloud thickness (Koren et al., 2004). Biomass burning particles may also have indirect effects through their interactions with cloud droplets, leading to a modification of the microphysics of the cloud, its lifetime and its precipitations (Twomey, 1974; Rosenfeld, 2000). Recent model studies (Gordon et al., 2018; Lu et al., 2018) suggest that the semi-direct and indirect effects of aerosols dominate the DRE over the SEAO, leading to a regional cooling.

Until recently, there has been a relative dearth of observations of biomass burning above clouds as passive sensor retrievals of aerosol and cloud are generally mutually exclusive. In past studies, biases in cloud properties derived from passive shortwave measurements were expected because the impact of aerosol absorption above clouds was not taken into account in the retrievals (Haywood et al., 2004). Over the last decade, techniques have been developed for the observation of aerosols above clouds. POLDER (Polarization measurements from POLarization and Directionality of the Earth's Reflectances) has been used to detect aerosols above clouds and to characterize the aerosol and the cloud layers by exploiting the sensitivity in polarized measurements (Waquet et al., 2013a, b; Peers et al., 2015). In the case of fine-mode absorbing aerosols overlying clouds, the absorption Ångström exponent leads to a greater impact on radiances reflected by the clouds at shorter wavelengths than longer ones (De Graaf et al., 2012; Torres et al., 2012). The "colour-ratio" approach has been applied to OMI (Ozone Monitoring Instrument Torres et al., 2012) and MODIS (Moderate Resolution Imaging Spectroradiometer - Jethva et al., 2013) to simultaneously retrieve the aerosol and the cloud optical thicknesses over the SEAO. Using a similar technique, the MODIS retrieval developed by Meyer et al. (2015) takes advantage of the six channels of the instrument from the UV to the shortwave infrared (SWIR) range to characterize not only the aerosol and cloud optical thicknesses, but also the cloud droplet effective radius. For the first time, these studies have provided large-scale observations of aerosols above clouds in the SEAO. However, these approaches have been applied to satellite instruments on polar-orbiting platforms that pro-

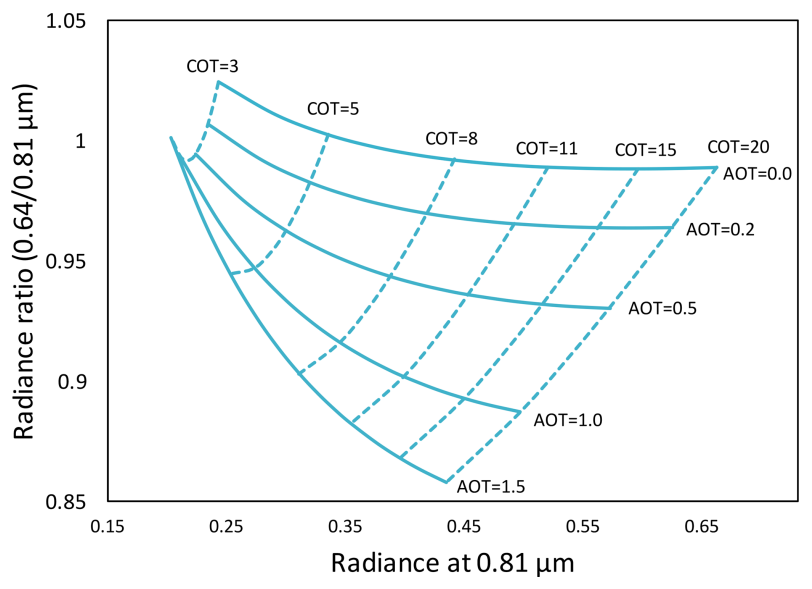

Figure 1. Radiance ratio $R_{0.64} / R_{0.81}$ as a function of the radiance at $0.81 \mu \mathrm{m}$ for absorbing aerosols above clouds simulated with the adding-doubling method (De Haan et al., 1987). COTs and AOTs are indicated at $0.55 \mu \mathrm{m}$.

vide only two observations per day for MODIS (on the Aqua and Terra platforms) and one for OMI and POLDER. The cloud cover over the SEAO has an important diurnal cycle which modulates the DRE of aerosols during the day (Min and Zhang, 2014). Therefore, the study of the SEAO cloud and above-cloud aerosol optical properties would benefit from the high-temporal-resolution observations provided by geostationary satellite platforms.

Chang and Christopher (2016) have highlighted the ability of SEVIRI (Spinning Enhanced Visible and Infrared Imager) to identify absorbing aerosols above clouds at high temporal resolution. The instrument is on board the geostationary satellite MSG (Meteosat Second Generation) and provides a full-disc observation every $15 \mathrm{~min}$, offering a unique opportunity to monitor the evolution of the cloud cover and to track aerosol plumes over the SEAO. The objective of this twopart paper is to demonstrate the potential of this instrument to simultaneously retrieve aerosol and cloud properties in the case of absorbing aerosols above clouds. In this first contribution, we describe the approach used to derive the above-cloud aerosol optical thickness (AOT), the cloud optical thickness (COT) and the cloud droplet effective radius (CER) and discuss the accuracy of the retrievals. The algorithm, as well as the atmospheric correction scheme and the assumed aerosol model, are presented in Sect. 2. The sensitivities in the retrieved quantities to the water vapour profile and the aerosol property assumptions are assessed in Sect. 3. The evaluation of the stability of the retrieval is shown in Sect. 4 and conclusions are drawn in Sect. 5. In a second companion paper, we will compare our SEVIRI-based retrievals of cloud and aerosol properties with those from MODIS products (Meyer et al., 2015) more comprehensively and also compare against in situ aircraft observations from the CLARIFY-2017 field campaign. 


\section{Retrieval method}

\subsection{Principle}

The approach used to retrieve aerosol and cloud properties from satellite spectral radiance measurements relies on the colour-ratio effect (Jethva et al., 2013). The signal backscattered by a liquid cloud is almost spectrally neutral from the UV to the near-infrared (NIR) ranges. Conversely, the absorption from biomass burning aerosols is typically larger at shorter wavelengths. Therefore, the presence of absorbing aerosols above clouds modifies the apparent colour of clouds. This enhancement of the spectral contrast can be detected by any passive remote-sensing instrument with two channels with enough separation in the UV-NIR region. The SEVIRI instrument, aboard the MSG satellite (Aminou et al., 1997), has channels centred at 0.64 , in the visible, and at $0.81 \mu \mathrm{m}$, in the NIR ranges. Figure 1 plots the $0.81 \mu \mathrm{m}$ radiance $\left(R_{0.81}\right)$ against the ratio of the 0.64 to $0.81 \mu \mathrm{m}$ radiances $\left(R_{0.64} / R_{0.81}\right)$, for absorbing aerosols above clouds over an ocean surface for several aerosol and cloud optical thicknesses. Throughout this paper, the radiances $R$ refer to the normalized quantity as defined by Herman et al. (2005) and the optical thicknesses (i.e. AOT, COT) are given at $0.55 \mu \mathrm{m}$. The simulations have been performed with the adding-doubling method (De Haan et al., 1987), considering a viewing geometry of $20^{\circ}$ for the solar zenith angle, $50^{\circ}$ for the viewing zenith angle and $140^{\circ}$ for the relative azimuth. The cloud is located between 0 and $1 \mathrm{~km}$ and the aerosol layer is between 2 and $3 \mathrm{~km}$. Aerosols have a refractive index of 1.54-0.025i and the size distribution follows a lognormal with a geometric mean radius of $0.1 \mu \mathrm{m}$. The cloud droplets have an effective radius of $10 \mu \mathrm{m}$. Rayleigh scattering has been accounted for but the simulations do not include the absorption from atmospheric gases. A Lambertian surface with an albedo of 0.05 is assumed. For AOT $=0$, the radiance ratio is around 1 and weakly depends on the COT. As the AOT increases, the radiance at $0.81 \mu \mathrm{m}$ as well as the radiance ratio decreases, indicating that the attenuation from the aerosol layer is larger at $0.64 \mu \mathrm{m}$. This attenuation is mainly due to the absorption from the aerosol layer, which means that it is primarily correlated to the absorption AOT (AAOT).

As in the Nakajima and King technique (1990), the sensitivity of the retrieval to the CER comes from the measurements of the shortwave infrared (SWIR) channel of SEVIRI centred at $1.64 \mu \mathrm{m}$. Figure 2 shows the radiances at 0.81 and $1.64 \mu \mathrm{m}$ for several COTs and CERs as well as the impact of overlying absorbing aerosols. The simulations without aerosol are plotted in blue and represent the signal typically used by cloud property retrievals that do not include light absorption from overlying aerosols. The orange and red grids are associated with an AOT of 0.5 and 1.5 at $0.55 \mu \mathrm{m}$. Compared to the no-aerosol case, these grids are shifted towards the upper left, which means that the presence of aerosols de-

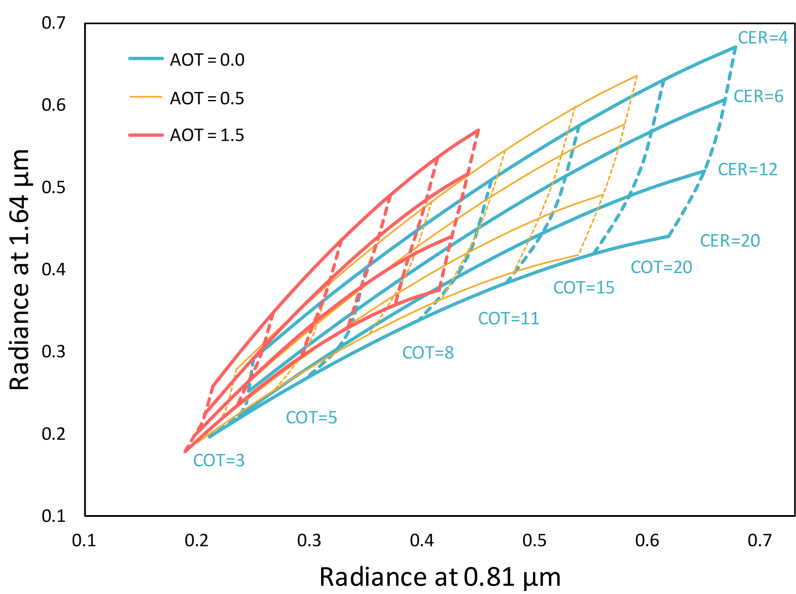

Figure 2. Simulated radiances at 1.64 and $0.81 \mu \mathrm{m}$ for clouds with varying COTs and CERs $(\mu \mathrm{m})$, without (blue) and with (orange and red) overlying absorbing aerosols above. The viewing geometry, the aerosol and the cloud properties are the same as in Fig. 1.

creases the NIR radiance and increases the SWIR signal. As highlighted by Haywood et al. (2004), not taking into account the aerosol absorption above clouds leads to low biases in both the COT and the CER. These biases depend on the aerosol loading as well as on the brightness of the underlying cloud.

Although the aerosol microphysical properties have some influence on the signal measured by satellites, this kind of approach requires us to assume an aerosol model. Fundamentally, the algorithm developed here aims to retrieve the above-cloud AOT, the COT and the CER from the magnitude and the gradient of the radiances measured by SEVIRI at $0.64,0.81$ and $1.64 \mu \mathrm{m}$ using a basic look-up table (LUT) approach and appropriate assumptions about the aerosol model for the region (Haywood et al., 2003) that have been refined based on measurements from the CLARIFY-2017 observational campaign (Zuidema et al., 2016).

\subsection{Atmospheric correction}

The SEVIRI channels chosen for the retrieval are fairly standard in atmospheric science and have been widely used for aerosol and cloud analysis (e.g. Brindley and Ignatov, 2006; Thieuleux et al., 2005; Watts et al., 1998). However, the SEVIRI bandwidths are much larger than other state-of-theart instruments such as MODIS. Hence, SEVIRI radiances are significantly more impacted by the absorption from various atmospheric gases. The spectral response functions for the $0.64,0.81$ and $1.64 \mu \mathrm{m}$ SEVIRI channels are plotted in Fig. 3 together with the equivalent MODIS bands. The main absorbing gases in these spectral bands are ozone, water vapour, methane and carbon dioxide, gases which are typically produced and transported within biomass burning plumes (Browell et al., 1996; Koppmann et al., 2005). The contributions of each gas to the atmospheric absorp- 


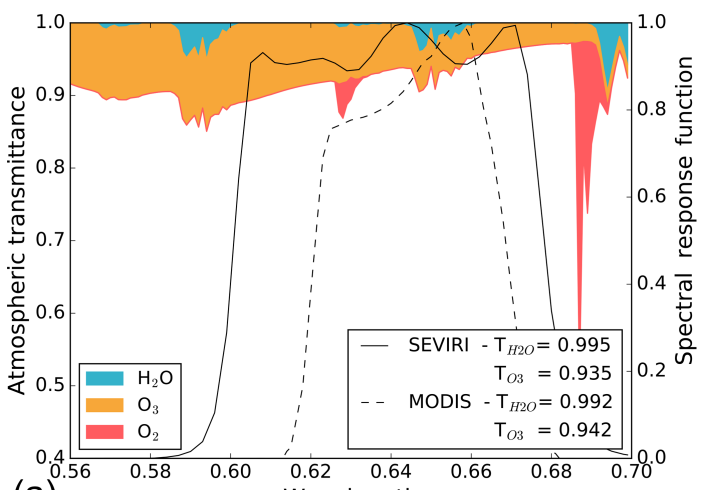

(a)
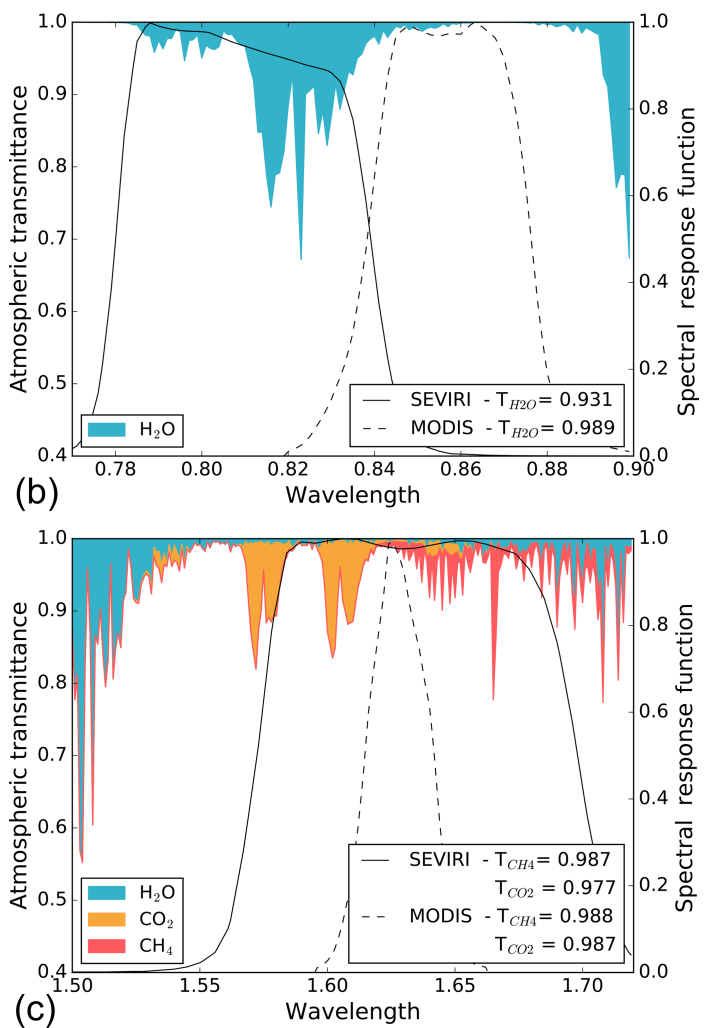

Figure 3. Spectral response function of the SEVIRI bands at 0.64 (a), 0.81 (b) and $1.64 \mu \mathrm{m}$ (c) with the corresponding MODIS ones (dashed lines) as well as the atmospheric transmittance within the spectral range (in colour). The transmittances have been calculated with the SOCRATES radiative transfer scheme (Manners et al., 2015; Edwards and Slingo, 1996) assuming a humidity profile measured during SAFARI (Keil and Haywood, 2003). In the legend of each plot, the transmittance weighted by the spectral response function is given for the main absorbing gases.

tion are also shown in Fig. 3 and the two-way transmittances (i.e. from the top of the atmosphere to the cloud top and from the cloud top to the top of the atmosphere) weighted by the spectral response function have been calculated. For the sake of simplicity, the two-way transmittances will be referred to as transmittances. Although the MODIS bandwidths are nar- rower than the SEVIRI ones, the weighted transmittances are similar for the 0.64 and $1.64 \mu \mathrm{m}$ channels. In the NIR, the MODIS central wavelength $(0.86 \mu \mathrm{m})$ is slightly larger than for SEVIRI $(0.81 \mu \mathrm{m})$ and the spectral band is only weakly impacted by the humidity, with a weighted transmittance of 0.989 . Within the SEVIRI band, water vapour absorption is much higher, with a transmittance of 0.931 . As a result, humidity has an impact on the spectral contrast between the VIS and the NIR, and therefore on the above-cloud AOT retrieval. The atmospheric correction, especially for the water vapour, is essential to accurately retrieve the aerosol and cloud properties from SEVIRI.

In order to correct the SEVIRI measurements for atmospheric absorption, the transmittances $T_{\mathrm{atm}, \lambda}$ are calculated for each spectral band $\lambda$ from the cloud top height to the top of the atmosphere using the fast radiative transfer model RTTOV (Matricardi et al., 2004; Hocking et al., 2014). The cloud top height is derived from the Met Office cloud property algorithm, which uses the $10.8,12.0$ and $13.4 \mu \mathrm{m}$ channels of SEVIRI (Francis et al., 2008; Hamann et al., 2014). Water vapour profiles come from the operational forecast configuration of the global Met Office Unified Model (Brown et al., 2012). This forecast is assimilated according to the scheme described by Clayton et al. (2013) that uses humidity data from various sources, including radiosondes and remote-sensing sounding data from many meteorological satellites. The forecast is run every $6 \mathrm{~h}$ and the humidity profile used for the atmospheric correction comes from the latest time-appropriate forecast field available. The profiles of the remaining gases - including ozone, carbon dioxide and methane - are those implicitly assumed by the RTTOV calculations (Matricardi, 2008). The radiance measured by SEVIRI $R_{\text {atm }, \lambda}$ is finally corrected using

$R_{\mathrm{atm}, \lambda}=T_{\mathrm{atm}, \lambda} R_{\lambda}$

where $R_{\lambda}$ is the radiance corrected from the gaseous absorption.

\subsection{Aerosol model}

The choice of the aerosol microphysical properties to use for the retrieval is similar to that of Haywood et al. (2003), but based on more comprehensive in situ measurements acquired during the CLARIFY-2017 field campaign. The Facility for Airborne Atmospheric Measurements (FAAM) BAe 146 aircraft was deployed in August-September 2017 operating from Ascension Island, with a main objective of studying biomass burning aerosol interactions with both radiation and clouds over the SEAO. This analysis focuses on flight C050, performed on 4 September, 2017. A profile descent from 7.3 to $1.9 \mathrm{~km}$ altitude was performed in order to sample the aerosol layer above clouds.

The aerosol dry extinction and absorption were measured with the EXSCALABAR instrument (EXtinction, SCattering and Absorption of Light for AirBorne Aerosol Research), 
which consists of a series of cavity ring-down and photoacoustic absorption cells operating at different wavelengths (Davies et al., 2018). From these in situ measurements, the single-scattering albedo (SSA) has been calculated at the instrument wavelengths of 405 and $658 \mathrm{~nm}$. The uncertainty in SSA calculations is related to the corresponding uncertainties in the extinction and absorption coefficients measured by EXSCALABAR. This error analysis has been performed previously and the reader is directed to Davies et al. (2019). Briefly, the measured extinction has an accuracy of $\sim 2 \%$, and we use a $2 \%$ extinction uncertainty in the analysis here. The errors in absorption measurements using photoacoustic spectroscopy depend on uncertainties in the ozone calibration, microphone pressure dependence and the background response from laser scattering/absorption on the windows of the photoacoustic cell. We have shown in recent publications that our calibration uncertainties are $\sim 5 \%$ (Cotterell et al., 2019; Davies et al., 2018), and the uncertainty in the pressure-dependent microphone response is $1.2 \%$ (Davies et al., 2019). The background response from laser-window interactions is from 0.27 to $0.54 \mathrm{Mm}^{-1}$. Thus, the total absorption uncertainty, propagating all the above uncertainties, is absorption-dependent and ranges from $29.0 \%$ to $55.0 \%$ (dependent on PAS measurement wavelength) at $1 \mathrm{Mm}^{-1}$ and $8.1 \%$ at $100 \mathrm{Mm}^{-1}$ (independent of PAS measurement wavelength). We propagated these total measurement uncertainties for both extinction and absorption measurements to derive the standard deviation $\sigma$ in our calculated SSA values. We find that the mean SSA uncertainties are 0.013 and 0.018 at the measurement wavelengths of 405 and $658 \mathrm{~nm}$ respectively.

The aerosol size distribution was characterized between 0.05 and $1.50 \mu \mathrm{m}$ radius using a wing-mounted passive cavity aerosol spectrometer probe (PCASP). Before and after the campaign, the bin sizes of the PCASP were calibrated using aerosolized diethyhexyl sebacate and polystyrene latex of known size and refractive index (Rosenberg et al., 2012). Further calculations based on Mie-scattering theory are performed in order to determine the bin sizes at the refractive index of the biomass burning aerosol sample. Partial evaporation of water is expected in the PCASP due to the heating of the probe, which may decrease the aerosol size. However, the sonde dropped during the flight indicates an average relative humidity above clouds of $29.2 \%$ with a maximum of $38.6 \%$. According to Magi and Hobbs (2003), the light scattering coefficient of an aged African biomass burning plume only increases by a factor of 1.01 for a relative humidity of $40 \%$. For this reason, the impact of humidity on the PCASP and EXSCALABAR measurements is neglected. Three sources of errors have been taken into account on the PCASP measurements: the error on the bin concentration is calculated according to Poisson counting statistics, the sample flow rate error is assumed to be $10 \%$ and a bin edge calibration error of half a bin has been considered.
The aerosol properties needed for the SEVIRI retrieval include the size distribution and the complex refractive index. The normalized number size distribution $(\mathrm{d} N / \mathrm{d} \ln r)$ is commonly represented by a combination of lognormal modes:

$$
\frac{\mathrm{d} N}{\mathrm{~d} \ln r}=\sum_{i} \frac{N_{i}}{\sqrt{2 \pi}} \frac{1}{\ln \sigma_{i}} \exp \left[\frac{-\left(\ln r_{i}-\ln r\right)^{2}}{2\left(\ln \sigma_{i}\right)^{2}}\right],
$$

where $N_{i}, r_{i}$ and $\sigma_{i}$ are the number fraction, the geometric mean radii and the standard deviation of the mode $i$ respectively. As in most remote-sensing applications, it has been chosen to represent the particle size distribution for the aerosol during CLARIFY-2017 with fine- and coarse-mode contributions. The aerosol optical properties are calculated using the Mie theory, as the spherical approximation is expected to be valid for biomass burning particles from $1 \mathrm{~h}$ after being released in the atmosphere (Martins et al., 1998). The aerosol model is selected by iteratively adjusting the refractive index and fitting the PCASP measurements (Fig. 4a) until the aerosol model matches the SSA from EXSCALABAR (Fig. 4b). In order to obtain the most suitable aerosol optical parameters for the retrieval, it is important to accurately fit the PCASP measurements where the aerosols contribute the most to the SEVIRI signal. Each bin of the PCASP has been assigned a weight for the fit of the bimodal distribution. The weights have been calculated in a similar way to Haywood et al. (2003), which means that they are proportional to the contribution of each bin to the total aerosol extinction in the $0.6 \mu \mathrm{m}$ band. The bins corresponding to the 0.15 to $0.25 \mu \mathrm{m}$ radius range contribute about $77 \%$ of the extinction. Consequently, these bins have been assigned appropriate larger weights during the fitting process of the size distribution. Due to the small fraction of coarse-mode aerosols, the standard deviation of this mode $\sigma_{\text {coarse }}$ could not be reliably fitted and has been set to a value of 2.23 , which is within the same order of magnitude as the one assumed for absorbing aerosol $(\sim 2.12)$ in the MODIS Dark Target operational algorithm (Levy et al., 2009).

The aerosol model that best represents the PCASP and EXSCALABAR measurements is shown in blue in Fig. $4 a$, b. A refractive index of 1.51-0.029i has been obtained, associated with an SSA of 0.85 at $0.55 \mu \mathrm{m}$, which is within the range of SSA measured over the SEAO during the SAFARI and the DABEX campaigns (Johnson et al., 2008) and on the upper end of the values from Ascension Island reported by Zuidema et al. (2018). Regarding the refractive index, it should be noted that the SSA is not very sensitive to the real part, suggesting that the value of 1.51 is not particularly well constrained. However, a real part of 1.51 is consistent with the AERONET retrievals for African biomass burning particles (Sayer et al., 2014) and is adopted here. The bestfit size distribution is characterized by $\left[R_{\text {fine }}, \sigma_{\text {fine }}, N_{\text {fine }}\right.$; $\left.R_{\text {coarse }}, \sigma_{\text {coarse }}, N_{\text {coarse }}\right]=[0.12 \mu \mathrm{m}, 1.42,0.9996 ; 0.62 \mu \mathrm{m}$, $2.23,0.0004]$. By way of comparison, the three-mode lognormal distribution obtained for aged biomass burning aerosols 

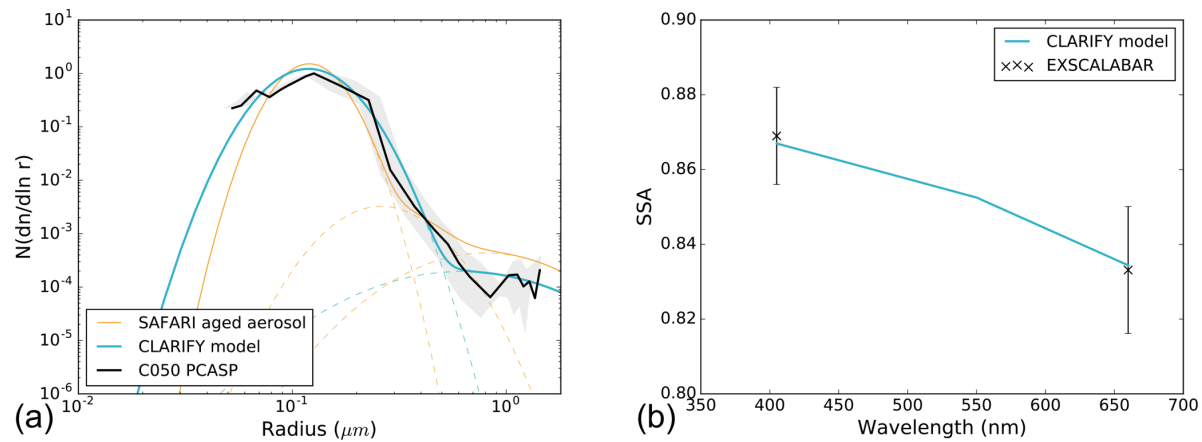

Figure 4. Normalized size distribution (a) and SSA (b) measured above clouds during flight C050 of the CLARIFY-2017 campaign (black). The grey shaded area represents the PCASP measurement and calibration uncertainties. Blue lines represent the fitted aerosol model, the orange lines correspond to the aged aerosol size distribution from SAFARI (Haywood et al., 2003), and the dashed lines show the contribution of each mode. CLARIFY-2017 aerosol model: $\left[R_{\text {fine }}, \sigma_{\text {fine }}, N_{\text {fine }} ; R_{\text {coarse }}, \sigma_{\text {coarse }}, N_{\text {coarse }}\right]=[0.12 \mu \mathrm{m}, 1.42,0.9996 ; 0.62 \mu \mathrm{m}, 2.23,0.0004]$, refractive index $=1.51-0.029 i$. SAFARI aged aerosol model: $\left[R_{1}, \sigma_{1}, N_{1} ; R_{2}, \sigma_{2}, N_{2} ; R_{3}, \sigma_{3}, N_{3}\right]=[0.12 \mu \mathrm{m}, 1.30,0.996 ; 0.26 \mu \mathrm{m}, 1.50$, 0.0033; $0.80 \mu \mathrm{m}, 1.90,0.0007]$.

during the SAFARI 2000 campaign (Haywood et al., 2003), defined by $\left[R_{1}, \sigma_{1}, N_{1} ; R_{2}, \sigma_{2}, N_{2} ; R_{3}, \sigma_{3}, N_{3}\right]=[0.12 \mu \mathrm{m}$, $1.30,0.996 ; 0.26 \mu \mathrm{m}, 1.50,0.0033 ; 0.80 \mu \mathrm{m}, 1.90,0.0007]$, is plotted in orange in Fig. 4a. The radius associated with the first mode is consistent with the CLARIFY-2017 model. The absence of the second fine mode in this study is compensated for by a larger standard deviation for the fine mode. Finally, the radius of the CLARIFY-2017 coarse mode is slightly smaller than the SAFARI-2000 one but the coarsemode fractions of the two models are close to each other. The uncertainties on the aerosol properties have been estimated using the errors on the PCASP and EXSCALABAR measurements. The uncertainty on the imaginary part of the refractive index is 0.02 for the real part and 0.004 for the imaginary part. For the size distribution, the uncertainty is $0.016 \mu \mathrm{m}, 0.09$ and 0.00045 for the radius, standard deviation and number fraction of the fine mode respectively.

\subsection{Algorithm}

The algorithm relies on the comparison of the corrected SEVIRI signal at $0.64,0.81$ and $1.64 \mu \mathrm{m}$ with precomputed radiances. The simulations have been performed using an adding-doubling radiative transfer code (De Haan et al., 1987). The surface is assumed to be Lambertian with an albedo of 0.05 at all wavelengths, which is typical of the sea surface albedo under diffuse radiation conditions. The aerosol and cloud properties assumed for the LUT are summarized in Table 1. The truncation of the cloud droplet phase function has been carried out using the delta-M method (Wiscombe, 1977) and the TMS correction (Nakajima and Tanaka, 1988) has been applied. The cloud layer is assumed to be located between 0 and $1 \mathrm{~km}$ and the aerosol layer between 2 and $3 \mathrm{~km}$. The sensitivity of the algorithm to the altitudes of the aerosol and cloud layers is expected to be negligible due to the small contribution of the Rayleigh scattering to the signal at the SEVIRI wavelengths. We have evaluated the error due to the fixed aerosol and cloud altitudes to be lower than $2.5 \%$ on the AOT and $0.3 \%$ on the cloud properties. The cloud droplets are assumed to follow a gamma law distribution characterized by an effective variance of 0.06 . When the cloud is optically thin and/or the cloud droplets are too small, it is not possible to separate the contribution to the optical signal arising from aerosols from that of clouds. Therefore, the minimum values for the CER and the COT in the LUT are 4 and $3 \mu \mathrm{m}$ respectively. This also justifies the assumption of a relatively simple sea surface reflectance parameterization as, at COTs exceeding 3 , the sea surface has little impact on the upwelling radiances above clouds. Clouds associated with lower COT and/or CER are rejected. The aerosol model corresponds to the CLARIFY-2017 model mentioned above, assuming the same refractive index at the three SEVIRI wavelengths.

The retrieval of the above-cloud AOT, COT and CER is performed simultaneously. The result corresponds to the parameters that minimize the difference $\varepsilon$ between the simulated radiances $R_{\text {sim }}$ and the corrected satellite signal $R_{\lambda}$ :

$\varepsilon=\sum_{\lambda}\left(\frac{R_{\lambda}-R_{\mathrm{sim}, \lambda}}{R_{\lambda}}\right)^{2}$.

When the simulated signal is not close enough to the satellite measurements (i.e. $\varepsilon>0.0006$ ), the result is rejected. The retrieval of the above-cloud AOT is highly uncertain at the cloud edges and for inhomogeneous clouds. In order to remove these results, the products are aggregated onto a $0.1^{\circ} \times 0.1^{\circ}$ grid and the standard deviation of the AOT and the CER are calculated. Note that each grid cell represents approximately 12 SEVIRI pixels. The inhomogeneity parameter $\rho$ is defined by the ratio of the standard deviation of a parameter to the average value of this parameter. The results corresponding to a standard deviation of the AOT larger than 
Table 1. Aerosol and cloud properties used to compute the radiances LUT of the SEVIRI retrieval.

\begin{tabular}{lrrrr}
\hline Aerosol model & \multicolumn{3}{c}{ Bimodal lognormal distribution } \\
\hline Size distribution & $R_{\text {fine }}=0.12 \mu \mathrm{m}$ & $\sigma_{\text {fine }}=1.42$ & $N_{\text {fine }}=0.9996$ \\
& $R_{\text {coarse }}=0.62 \mu \mathrm{m}$ & $\sigma_{\text {coarse }}=2.23$ & $N_{\text {coarse }}=0.0004$ \\
\cline { 2 - 5 } & $0.55 \mu \mathrm{m}^{*}$ & $0.64 \mu \mathrm{m}$ & $0.81 \mu \mathrm{m}$ & $1.64 \mu \mathrm{m}$ \\
\hline Refractive index & 0.852 & 0.839 & 0.804 & 0.643 \\
Wavelength & 0.649 & 0.612 & 0.538 & 0.468 \\
SSA & \multicolumn{5}{c}{$1.51-0.029 i$} \\
\hline Cloud model & \multicolumn{5}{c}{ Gamma law } \\
\hline Size distribution & $R_{\text {eff }}$ from 4 to $60 \mu \mathrm{m}$ \\
\cline { 2 - 5 }
\end{tabular}

* Note that $0.55 \mu \mathrm{m}$ does not correspond to a SEVIRI channel.
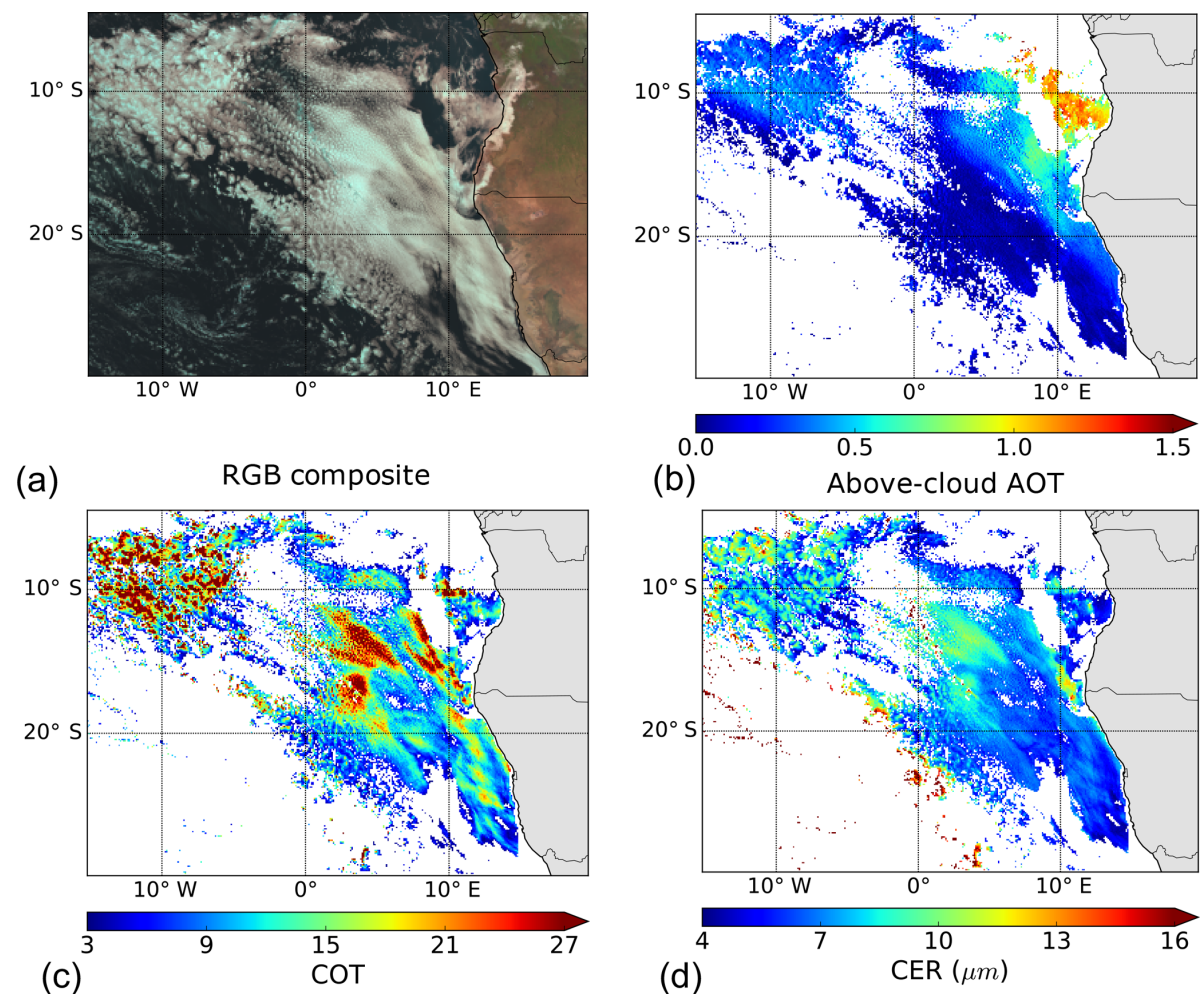

Figure 5. RGB composite (a), above-cloud AOT at $0.55 \mu \mathrm{m}$ (b) and cloud properties (c and d) retrieved from SEVIRI measurements on 28 August 2017 at 10:12 UTC over the SEAO.

0.7 and/or $\rho_{\mathrm{CER}}>0.2$ as well as grid cells associated with fewer than nine successful retrievals are rejected.

It is important to realize that the uncertainties that we quantify here are structural and parametric uncertainties related to assumptions made in the retrieval algorithm. When using a fixed aerosol model, no account is made for natural variability in the aerosol optical parameters and the associ- ated uncertainty; this is dealt with in the uncertainty analysis that follows. 


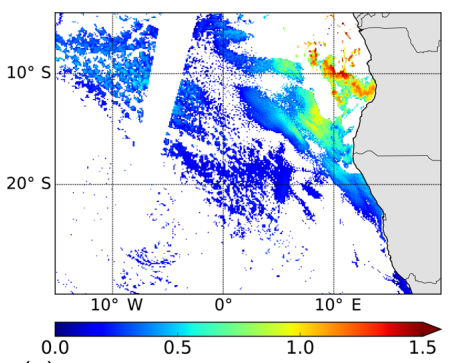

(a)

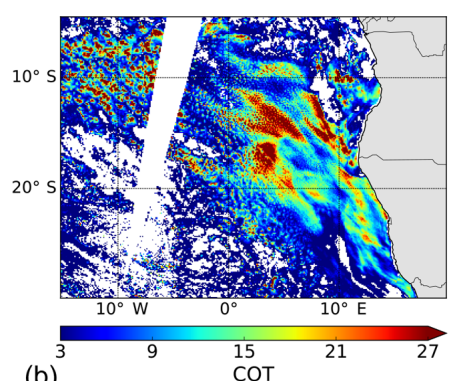

(b)

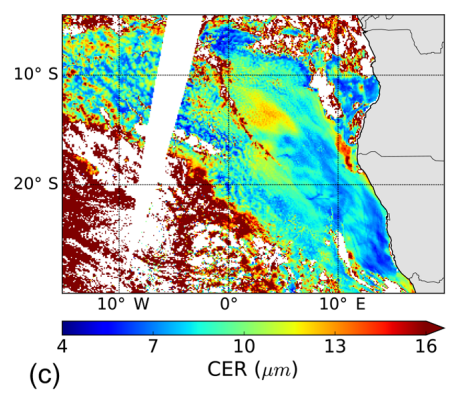

(c)

Figure 6. Above-cloud AOT at $0.55 \mu \mathrm{m}$ (a) and cloud properties (b and c) retrieved from MODIS Terra with the MOD06ACAERO algorithm (Meyer et al., 2015) on 28 August 2017.

\section{Results and uncertainty analysis}

\subsection{Case study}

The algorithm has been applied to an event of biomass burning aerosols above clouds captured by SEVIRI on 28 August 2017 at 10:12 UTC. The RGB composite and the retrieved above-cloud AOT, COT and CER over the SEAO region are shown in Fig. 5. The largest AOTs are observed off the coast of Angola, with a local average value of 1.0 and a maximum of 1.6 at $0.55 \mu \mathrm{m}$. The AERONET site of Lubango $\left(14.96^{\circ} \mathrm{S}-\right.$ $13.45^{\circ} \mathrm{E}$ ) measured an average AOT of 0.75 that day with an Ångström exponent of 1.83, indicating the expected domination of fine-mode biomass burning aerosols. A gradient of AOT is observed towards the south-west, as we move away from the source as might be expected from a pre-campaign analysis of satellite retrievals (Zuidema et al., 2016). Absorbing aerosols above clouds are also detected in the northwest part of the region. Around Ascension Island $\left(7.98^{\circ} \mathrm{S}-\right.$ $14.42^{\circ} \mathrm{W}$ ), the above-cloud AOT from SEVIRI is around 0.37 while the AERONET site indicates a value of 0.48 associated with an Ångström exponent of 1.271. This suggests that coarse-mode aerosols, such as sea salt within the boundary layer but generally below cloud, are contributing to the total column aerosol load. The cloud properties retrieved are within the range of values typically observed for marine stratocumulus (Szczodrak et al., 2001) with more than $90 \%$ of the COT lower than 25 and $99 \%$ of the CER between 4 and $20 \mu \mathrm{m}$. As a comparison, Fig. 6 shows the equivalent aerosol and cloud properties retrieved from MODIS Terra with the MOD06ACAERO algorithm (Meyer et al., 2015) for the 10:00 and 11:30 UTC overpasses. The MODIS above-cloud AOT pixels associated with an uncertainty larger than $100 \%$ have been removed. A good spatial agreement is observed between the two satellite products. The above-cloud AOT from MODIS is also 1.0 on average close to the coast. On average over the area, the MODIS above-cloud AOT is larger by 0.05 compared to SEVIRI. Considering that MODIS is less sensitive to the atmospheric absorption and that the two algorithms are based on the same principle, the small differences observed between the two above-cloud AOT tend to validate the atmospheric correction applied to the SEVIRI measurements for that case. There is a good consistency between the MODIS and the SEVIRI COT. Finally, the CER retrieved with the MOD06ACAERO algorithm is larger by $2.2 \mu \mathrm{m}$ compared to the SEVIRI CER. This almost systematic difference is mainly due to differences in the satellite instruments, and especially the difference in the channels used for the retrieval (Platnick, 2000). A fully statistical analysis against the MODIS algorithm, and against airborne remotesensing and in situ measurements will be presented in a companion paper.

\subsection{Atmospheric correction}

The atmospheric transmittances above clouds used to correct the SEVIRI measurements from the gas absorption are calculated based on forecast water vapour profiles. In order to assess the sensitivity of the retrieval to the atmospheric correction, new transmittances have been calculated for the event studied here, modifying the specific humidity by $\pm 10 \%$. The aerosol and cloud properties retrieved with the modified atmospheric corrections are aggregated on a $0.1^{\circ} \times 0.1^{\circ}$ grid. Figure 7 compares the retrieved aerosol and cloud properties from SEVIRI-measured radiances using the original specific humidity forecast with the perturbed specific humidity $(+10 \%$ in orange and $-10 \%$ in blue). The uncertainty on the water vapour content impacts mainly the retrieval of the above-cloud AOT, and then the COT, because of its effect on the radiance ratio. $\mathrm{A}+10 \% /-10 \%$ bias on the humidity leads to an overestimation/underestimation of the AOT and COT respectively. On average, errors of $18.5 \%$, $5.5 \%$ and $2.3 \%$ have been calculated for the AOT, COT and CER respectively, based on biases of $10 \%$ in the specific humidity forecast. These errors are likely upper estimates because forecast errors in specific humidity are unlikely to reach these values owing to the extensive assimilation of satellite data and sonde profiles by the data assimilation process used in the Met Office forecast model as previously mentioned. However, the differences between forecast model specific humidities and those of simple standard atmosphere climatological values (e.g. those of McClatchey et 
al., 1972) frequently exceed $10 \%$, indicating that accurate retrievals of aerosol and cloud need synergistic retrievals or data-assimilated forecasts of specific humidity.

\subsection{Aerosol model}

The LUT used for the SEVIRI retrieval uses an assumed aerosol model based on in situ measurements from CLARIFY-2017. However, the absorption property and the size of biomass burning particles are expected to vary during the fire season and across the SEAO (e.g. Eck et al., 2003). Here, we analyse the impact of the aerosol assumptions on the retrieved aerosol and cloud properties.

In order to create a range of aerosol optical properties, a thousand aerosol models have been processed using the Mie theory. The radius and the standard deviation of the fine mode and the real and imaginary part of the refractive index of the models are random values following a normal distribution. Their mean corresponds to the CLARIFY model values provided in Table 1, with standard deviations of $0.01 \mu \mathrm{m}$ and 0.1 for the radius and the standard deviation of the fine mode, 0.02 for the real part of the refractive index, and 0.008 for the imaginary part. Figure $8 \mathrm{a}$ and $\mathrm{b}$ show the histograms of the simulated SSA and asymmetry factor $g$ at $0.55 \mu \mathrm{m}$ in orange. As a comparison, histograms of the AERONET SSA and $g$ are plotted in blue. The data correspond to the AERONET level 2.0 retrievals for August-September, from 1997 to 2018 and for inland sites of southern Africa $\left(10-35^{\circ} \mathrm{S}, 10-40^{\circ} \mathrm{E}\right)$. Only data associated with an Ångström exponent larger than 1.0 have been used in order to remove measurements dominated by coarse-mode particles (such as dust and sea salt) that are less likely to be observed above clouds in the SEAO. The mean SSA (0.862) and the mean $g$ (0.620) from AERONET are respectively slightly larger and smaller than the CLARIFY model. Small differences between above-cloud and full column aerosol properties could be explained by the contribution of aerosol within the boundary layer, such as pollution, desert dust and sea salt. The dashed lines in Fig. 8a and $\mathrm{b}$ represent the mean \pm the standard deviation of SSA and $g$. The AERONET standard deviation is 0.023 for the SSA and 0.024 for $g$ while the simulation produces a standard deviation of 0.036 for the SSA and 0.041 for $g$. The simulated range of both optical properties is larger than the range observed by AERONET. Therefore, the variation in the aerosol microphysical properties used for the simulations is wide enough to cover the range of observed aerosol optical properties.

From the simulated standard deviation $\sigma$ of $g$ and SSA, eight aerosol models have been defined and their properties are summarized in Table 2. The first four are used to test the sensitivity of the retrieval to $g$ and SSA independently ([SSA $\left.{ }_{\text {CLARIFY }} \pm \sigma_{\text {SSA }}, g_{\text {CLARIFY }}\right]$ and [SSA CLARIFY, $\left.g_{\text {CLARIFY }} \pm \sigma_{g}\right]$ ) and the sensitivity to both parameters will be assessed with the last four ([SSA CLARIFY $\pm \sigma_{\mathrm{SSA}}, g_{\mathrm{CLARIFY}} \pm$ $\left.\left.\sigma_{g}\right]\right)$. New LUTs have been processed with these modified aerosol models and used to re-process the case study from Sect. 3a. After aggregating the data on a $0.1^{\circ} \times 0.1^{\circ}$ grid, the AOT as well as the absorption AOT (AAOT), the COT and the CER are compared against those obtained with the standard CLARIFY-2017 aerosol model. Results are shown in Figs. 9 and 10. For each aerosol and cloud property, a linear relationship is observed between the retrieval using the standard CLARIFY-2017 aerosol model and the modified one. The retrieval of cloud properties (Figs. 9c, d and 10c, d) appears to be weakly sensitive to the assumed aerosol model, with $g$ having a slightly larger impact. On average, differences lower than $4.1 \%$ are observed on the COT and lower than $2.4 \%$ on the CER. As expected, the choice of the aerosol model has much more influence on the AOT retrieval. The uncertainty on the AOT is dominated by the SSA assumption. When aerosols are more absorbing than the CLARIFY model, the algorithm overestimates the AOT by $25.7 \%$. Conversely, the retrieved AOT is underestimated by $32.6 \%$ when aerosols are less absorbing than the CLARIFY model. The impact of $g$ alone on the retrieved AOT is far less significant and lower than $4.3 \%$. Figure 9a, which shows the impact of a perturbation on both the SSA and $g$, confirms that the SSA is the parameter with the strongest influence on the AOT retrieval. The largest overestimation $(27.5 \%)$ is observed when both the SSA and $g$ are overestimated (Fig. 10a), while the largest underestimation $(-33.3 \%)$ is obtained when the SSA is underestimated and $g$ is overestimated. The retrieval of the above-cloud AOT depends mostly on the aerosol absorption of the light reflected by the cloud. Therefore, it is expected that the retrieved AAOT is less sensitive to the absorbing property of the aerosol than the AOT. The sensitivity of the AAOT to the assumed aerosol properties is shown in Figs. 9b and 10b. The uncertainty in the AAOT due to an error in $g$ is similar to the uncertainty in the AOT $(<5 \%)$. However, the influence of the SSA assumption alone on the AAOT is smaller than the influence on the AOT, with differences of $1.9 \%$ and $-8.7 \%$. This means that a perturbation of the SSA primarily impacts the scattering AOT. The largest overestimation of the AAOT $(2.7 \%)$ is obtained when the assumed aerosol model overestimates $g$. An underestimation of the SSA and an overestimation of $g$ lead to the largest underestimation of the AAOT $(-5.1 \%)$

The variation in the solar zenith angle, and therefore in the satellite observation geometry during the day, can impact the sensitivity of the retrieval to the aerosol assumptions. Therefore, the $15 \mathrm{~min}$ SEVIRI observations for $28 \mathrm{Au}-$ gust have been processed using the eight aerosol models described above and compared to the aerosol and cloud properties retrieved with the CLARIFY aerosol model. The difference $\Delta x_{i}$ of a product $x$ is defined as

$\Delta x_{i}=\left(x_{\mathrm{CLARIFY}}-x_{i}\right) / x_{i} \times 100 \%$,

where $x_{\text {CLARIFY }}$ and $x_{i}$ is the mean product $x$ retrieved over the SEVIRI slot with the aerosol CLARIFY model and the 


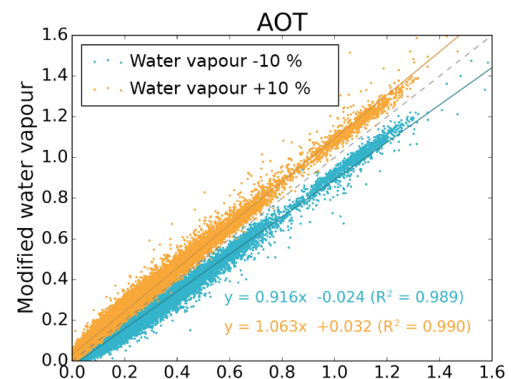

(a)

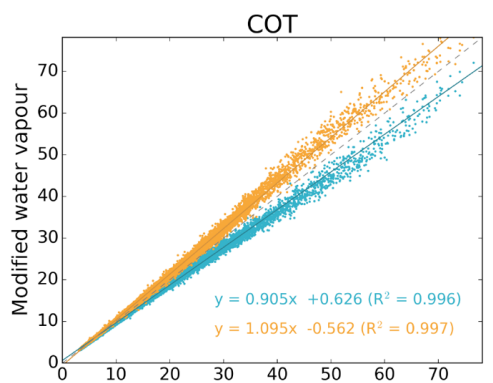

(b)

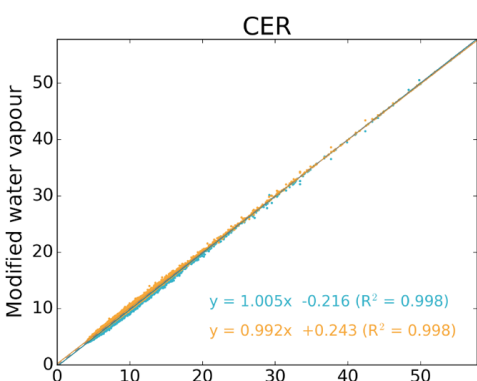

(c)

Figure 7. Uncertainty in the retrieved above-cloud AOT (a), COT (b) and CER (c) due to an error of $+10 \%$ in orange and $-10 \%$ in blue on the specific humidity profile compared to the original forecast for 28 August 2017 at 10:12 UTC.

Table 2. Aerosol properties used to test the sensitivity of the SEVIRI retrieval to the aerosol model assumption. SSA and $g$ are given at $0.55 \mu \mathrm{m}$.

\begin{tabular}{lrrrrr}
\hline Model & SSA & $g$ & $R_{\text {fine }}$ & $\sigma_{\text {fine }}$ & Refr. index \\
\hline CLARIFY & 0.852 & 0.649 & 0.12 & 1.42 & $1.51-0.029 i$ \\
\hline SSA $_{\text {CLARIFY }}-\sigma_{\text {SSA }}$ & 0.812 & 0.648 & 0.12 & 1.42 & $1.51-0.037 i$ \\
SSA $_{\text {CLARIFY }}+\sigma_{\text {SSA }}$ & 0.891 & 0.649 & 0.12 & 1.42 & $1.52-0.021 i$ \\
$g_{\text {CLARIFY }}-\sigma_{g}$ & 0.852 & 0.603 & 0.12 & 1.30 & $1.53-0.027 i$ \\
$g_{\text {CLARIFY }}+\sigma_{g}$ & 0.851 & 0.686 & 0.12 & 1.51 & $1.50-0.030 i$ \\
\hline SSA $_{\text {CLARIFY }}-\sigma_{\text {SSA }}, g_{\text {CLARIFY }}-\sigma_{g}$ & 0.813 & 0.604 & 0.11 & 1.37 & $1.52-0.034 i$ \\
SSA $_{\text {CLARIFY }}+\sigma_{\text {SSA }}, g_{\text {CLARIFY }}+\sigma_{g}$ & 0.886 & 0.687 & 0.13 & 1.50 & $1.49-0.022 i$ \\
SSA $_{\text {CLARIFY }}-\sigma_{\text {SSA }}, g_{\text {CLARIFY }}+\sigma_{g}$ & 0.814 & 0.684 & 0.12 & 1.51 & $1.50-0.041 i$ \\
SSA $_{\text {CLARIFY }}+\sigma_{\text {SSA }}, g_{\text {CLARIFY }}-\sigma_{g}$ & 0.884 & 0.602 & 0.11 & 1.36 & $1.49-0.017 i$ \\
\hline
\end{tabular}
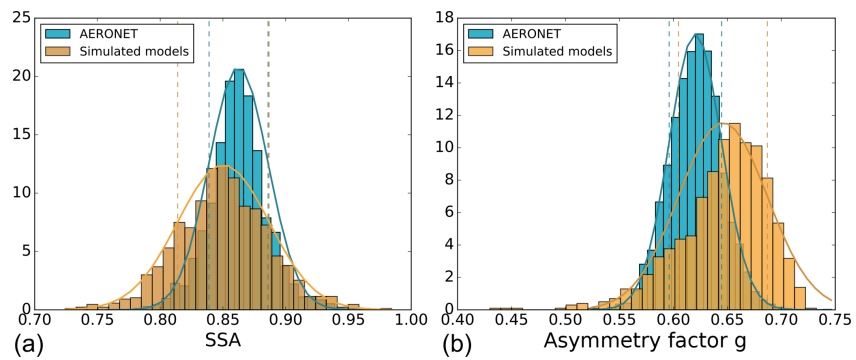

Figure 8. Histograms of the SSA (a) and asymmetry factor $g(\mathbf{b})$ at $0.55 \mu \mathrm{m}$ simulated from a range of size distributions and refractive indices (orange) and retrieved by AERONET (blue) over southern Africa. Dashed lines represent the mean \pm the standard deviation.

modified model $i$ respectively. Figure 11 shows the time series of $\triangle$ AOT (a), $\triangle$ AAOT (b), $\triangle \mathrm{COT}$ (c) and $\triangle \mathrm{CER}$ (d) obtained with the modified aerosol models. The sensitivity of the retrieved cloud properties to the aerosol model assumptions remains small (lower than $5.6 \%$ for the COT and $2.6 \%$ for the CER) and dominated by the sensitivity to $g$. Apart from a small decrease in $\triangle$ COT at midday when $g$ is overestimated (solid blue line) and an increase in $\triangle \mathrm{COT}$ in late afternoon when the SSA is underestimated (solid red line), no significant trend is observed in the cloud property sensi- tivities. As observed previously, the uncertainty on the AOT is led by the SSA assumption, with the AOT being overestimated (respectively underestimated) when the assumed SSA is overestimated (respectively underestimated). Until 15:00, $\triangle$ AOT stays within $\pm 40 \%$, with the sensitivity to the SSA being slightly larger at midday. Then it increases up to $60 \%$ when the SSA is overestimated and $g$ is underestimated (dashed blue line). Similar trends are observed in $\triangle \mathrm{AAOT}$, with generally lower values than $\triangle \mathrm{AOT}$. An increase in the uncertainty is observed on the AAOT after 15:00, which reaches up to $27 \%$ at 16:30. Before 15:00, there is a larger AAOT sensitivity to the SSA around midday $(+8.9 \% /-15.2 \%)$, but there is no evident evolution of the sensitivity to $g$ with time. The case that leads to the largest biases on the AAOT is when the SSA is underestimated and $g$ overestimated (dashed green lines), with an underestimation of up to $23 \%$. However, it should be noted that $0 \%$ of the AERONET observations used in Fig. 8 are associated with an SSA lower than SSA CLARIFY $-\sigma_{\mathrm{SSA}}$ and a $g$ larger than $g_{\text {CLARIFY }}-\sigma_{g}$. Otherwise, the sensitivity of the AAOT to the aerosol property assumptions stays between -16.6 and $+9 \%$ before 15:00.

In conclusion, the retrieved AOT is less sensitive to the aerosol property assumption before 15:00, with an uncertainty of $40 \%$. This uncertainty is dominated by the sensi- 

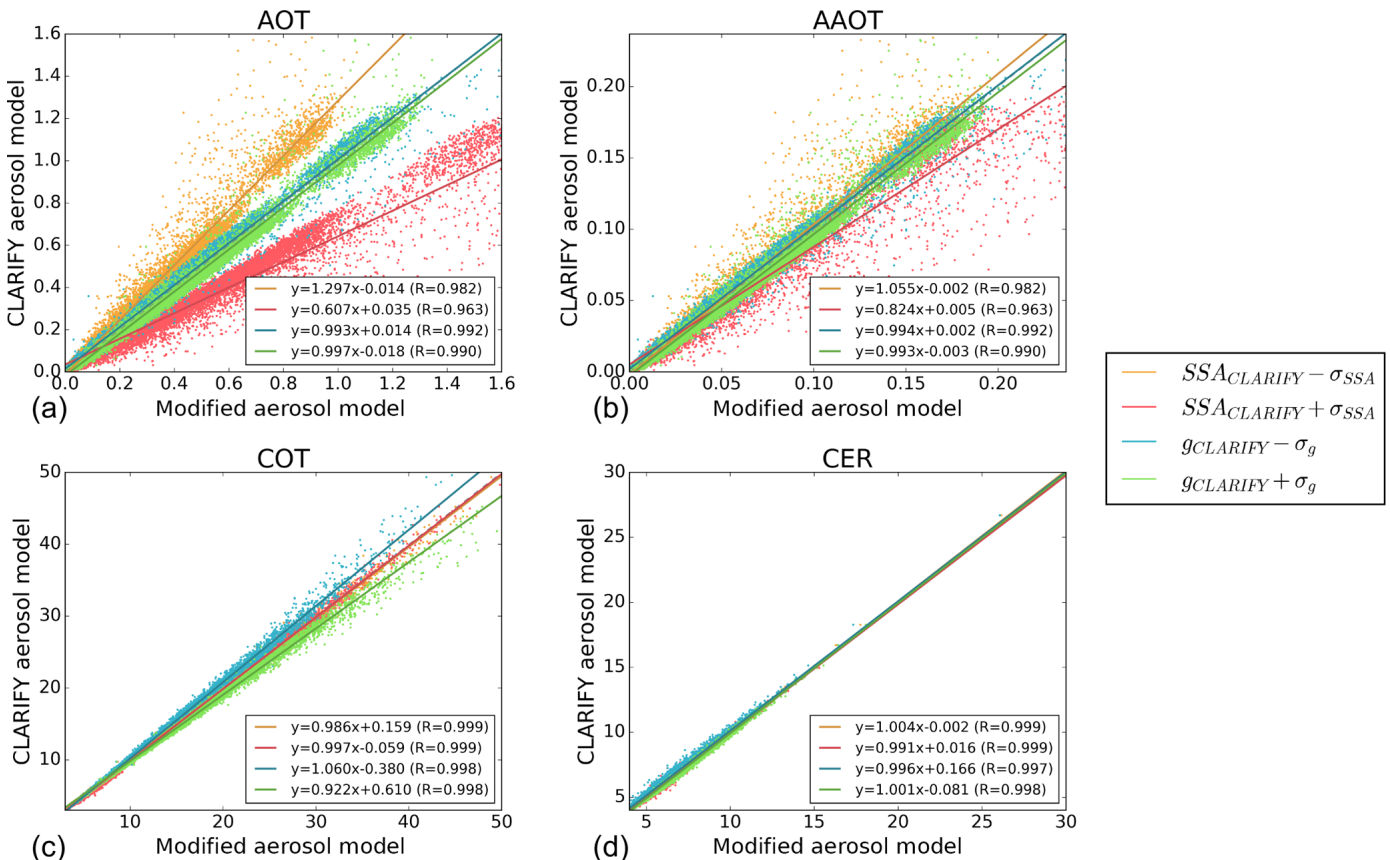

Figure 9. Impact of the assumption on the SSA and the asymmetry factor $g$ on the retrieved aerosol and cloud properties. AOT, AAOT, COT and CER obtained for 28 August 2017 at 10:12 UTC with the CLARIFY-2017 model are plotted against the properties retrieved with the modified aerosol models.
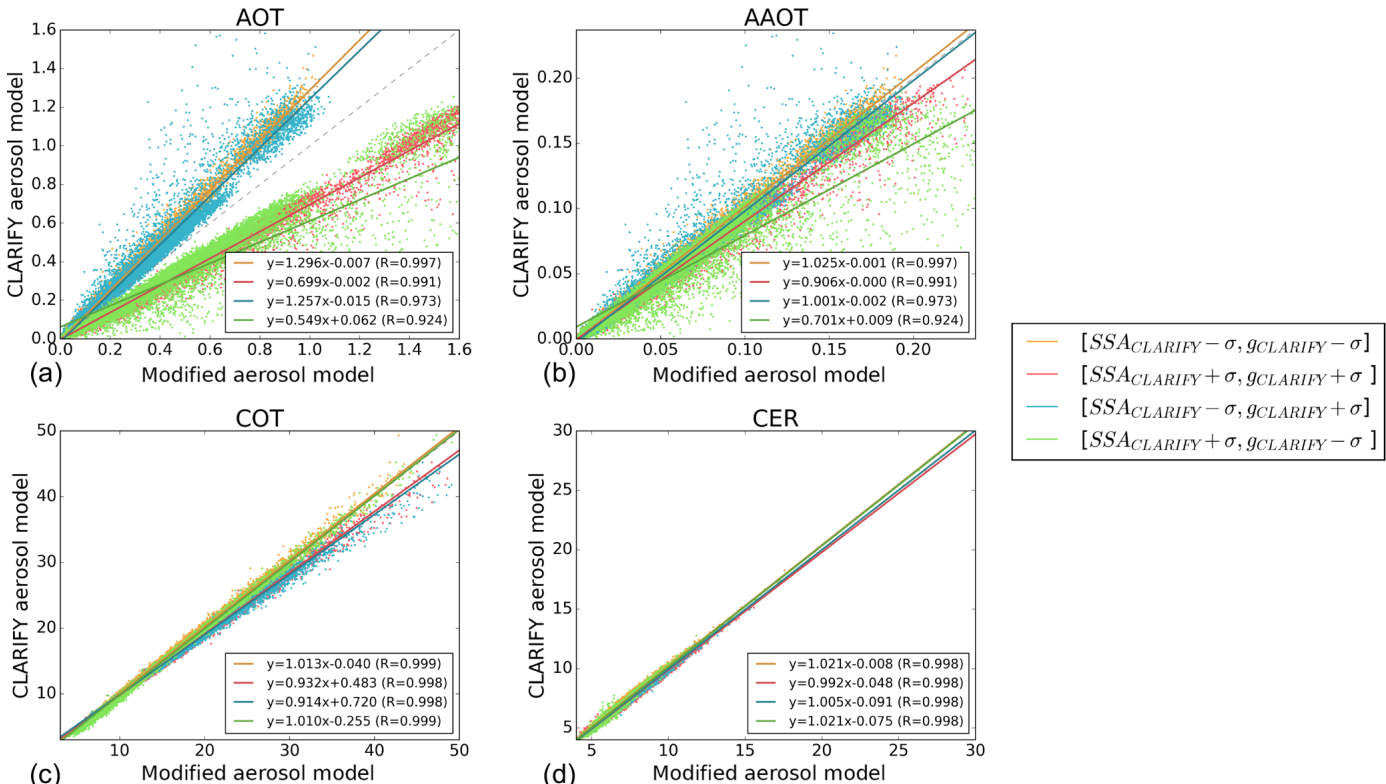

Figure 10. Similar to Fig. 9 but for the combined impact and the SSA.

tivity of the retrieval to the SSA. An overestimation (respectively underestimation) of the AOT is expected when the observed aerosols are more (respectively less) absorbing than the aerosol model assumed for the retrieval. A better accuracy is obtained on the retrieved AAOT, with an uncertainty generally lower than $17 \%$ before 15:00. The sensitivity of the cloud properties to the aerosol model assumption remains small all day long, with an uncertainty of $5.6 \%$ on the COT and $2.6 \%$ on the CER. 


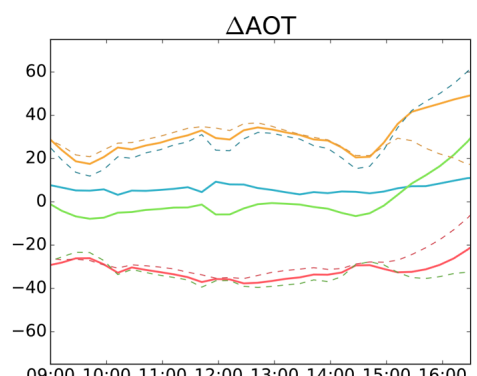

(a)

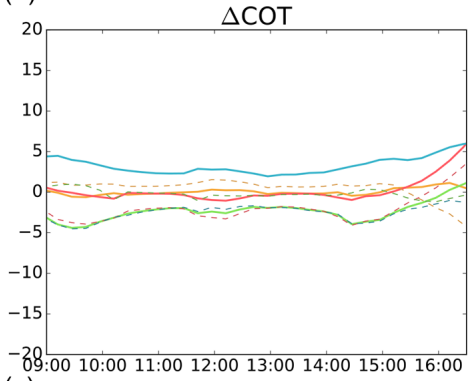

(c)

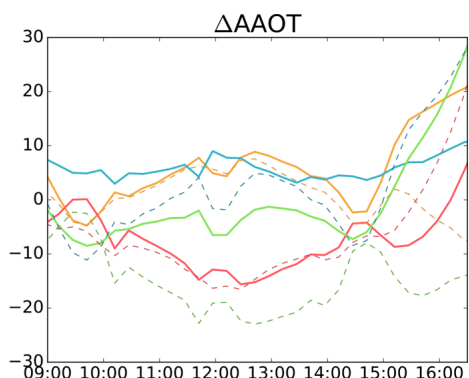

(b)

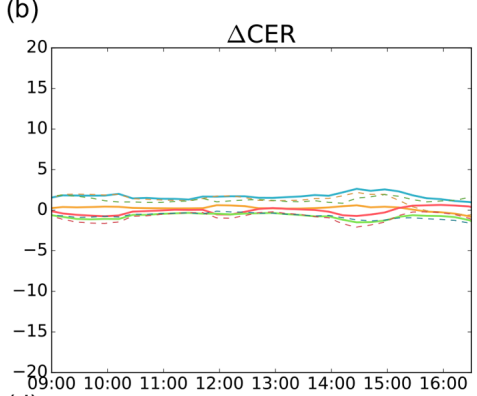

(d)

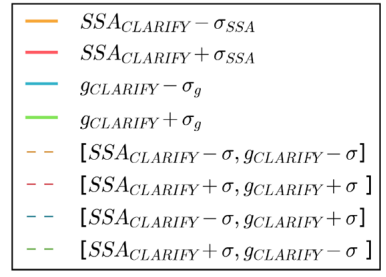

Figure 11. Time series (UTC) of the difference $\Delta(\%)$ of the above-cloud AOT (a), AAOT (b), COT (c) and CER (d) retrieved with the CLARIFY model and the modified aerosol models for 28 August 2017.

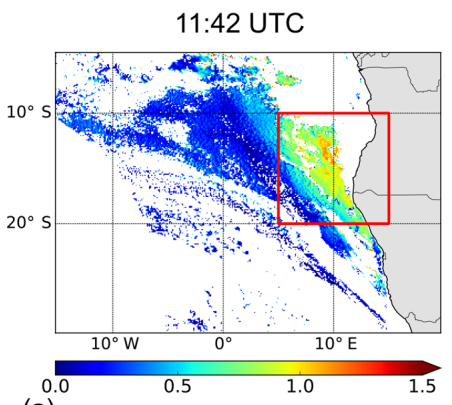

(a)

Above-cloud AOT

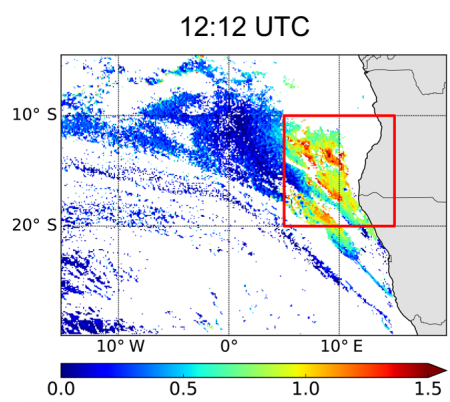

(b)

Above-cloud AOT

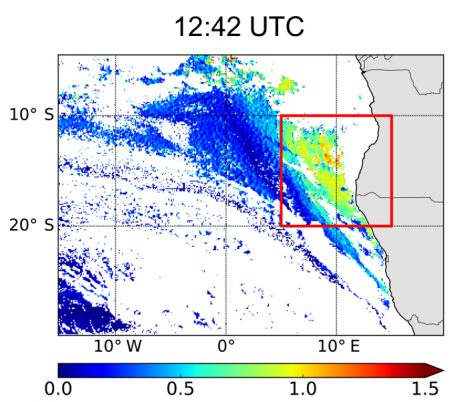

(c)

Above-cloud AOT

Figure 12. Above-cloud AOT retrieved on 5 September 2017 at 11:42, 12:12 and 12:42 UTC. The red square represents the area over which the SEVIRI products have been averaged.

\section{Assessing the stability of the retrieval}

One of the major benefits from using SEVIRI is the ability to track both aerosol and cloud events at high temporal resolution. Therefore, it is important to evaluate how consistent the retrieval is over time. For that purpose, $2 \mathrm{~d}$ of continuous observations (i.e. 5 and 6 September 2017) have been analysed and the retrieved properties have been averaged over 20 and $10^{\circ} \mathrm{S}$ and 5 and $15^{\circ} \mathrm{E}$, which correspond to the red square on the maps in Fig. 12. The above-cloud AOT, COT and CER time series are presented in Fig. 13a, b, c. The studied area is located next to the coast, where the AOT is typically the highest. The above-cloud AOT is around 0.66 and 0.72 for 5 and 6 September respectively. As expected, the transport of the aerosol plume from east to west is slow, resulting in a small evolution of the above-cloud AOT. On both days, a peak is observed at 12:12 with an anomaly larger than the AOT variability. This localized discontinuity in the above-cloud AOT is shown in the 11:42, 12:12 and 12:42 UTC maps for 5 September 2017 in Fig. 12. The evolution of the cloud properties is slightly more complex. A small decrease is observed in both the COT and CER until 14:00. After 15:00, both properties sharply increase. The clouds are strongly affected by the diurnal cycle and a shoaling of the cloud cover is expected from early morning to late afternoon. As the thinnest clouds vanish, the cloud fraction decreases together with the number of retrievals in the area. This results in a larger contribution of the thickest clouds to the mean value in the late afternoon. As for the above-cloud AOT, large variations in the CER are observed around noon. At that time, the sun and the satellite are almost aligned and the scattering angle (Fig. 13d) reaches values larger than $175^{\circ}$, which corresponds to the region where the glory phenomenon is typically observed. Several reasons can explain why the retrieval does not perform 
well in backscattering direction. The first one is the uncertainty in the LUT due to the truncation of the cloud phase function. Although the TMS correction gives good results, biases still remain in the glory aureole (Iwabushi and Suzuki, 2009). Also, the radiances in the glory are more sensitive to the cloud droplet microphysics (Mayer et al., 2004). The assumption on the variance of the droplet size distribution may induce biases in the retrieval. Therefore, the accuracy of the retrieval cannot be guaranteed within the glory aureole and these observations should be discarded. In Fig. 13, the time spans corresponding to the MODIS Aqua and Terra overpasses in the region are highlighted in orange. This shows that MODIS measurements are typically performed before and after SEVIRI observes the glory backscattering over the SEAO, usually allowing comparisons between these instruments.

The performance of the algorithm is further assessed by evaluating the stability of the retrieved above-cloud AOT at pixel level. As noted by Chang and Christopher (2016), in this region over these scales, aerosols are expected to have a limited temporal variability and the variation in the above-cloud AOT is expected to be small between $t=0$ and $t \pm 15 \mathrm{~min}$. The differences between the AOT retrieved at $t=0$ and the running mean estimated between $t-15$ and $t+15 \mathrm{~min}$ have been calculated at pixel level for observations between 09:00 and 15:00 UTC, removing measurements within the glory backscattering region. Figure 14 shows the histogram of the AOT differences calculated over a $12 \mathrm{~d}$ period (1 to 12 September 2017). The differences follow a normal distribution centred around 0.0 with a standard deviation of 0.1 . This short-term variability can be attributed to several sources of uncertainties, such as the total amount of water vapour, its vertical distribution, the retrieved cloud top height and the numerical fitting procedure. This analysis indicates that the retrieval of the above-cloud AOT remains relatively stable, with an observed variability of \pm 0.1 between consecutive observations. Except for the glory backscattering, the stability observed on the retrieved aerosol and cloud properties reinforces the reliability of the algorithm.

\section{Conclusions}

Recently, progress has been made in the remote-sensing field in order to fill the lack of aerosol above-cloud observations. Techniques have been developed to retrieve aerosol and cloud properties over the SEAO from passive remote-sensing instruments. These algorithms take advantage of the colourratio effect (Jethva et al., 2013), which is the spectral contrast produced by the aerosol absorption above clouds. Although OMI (Torres et al., 2012), MODIS (Jethva et al., 2013; Meyer et al., 2015) and POLDER (Peers et al., 2015) already provide useful information about aerosols above clouds, these instruments are on polar-orbiting satellites and their low temporal resolutions prevent monitoring the diurnal variation in the cloud cover and in the DRE of aerosols over the SEAO. For the first time, we have applied a similar algorithm to geostationary measurements from the SEVIRI instrument, which has a repeat cycle of $15 \mathrm{~min}$. The method consists of a LUT approach, using the channels at $0.64,0.81$ and $1.64 \mu \mathrm{m}$ in order to simultaneously retrieve the above-cloud AOT, COT and CER.

Compared to other satellite instruments, the SEVIRI measurements are more sensitive to the absorption from atmospheric gases because of their wider spectral bands. Therefore, an efficient atmospheric correction scheme is essential in order to separate the absorption from the aerosols and from the atmospheric gases. Atmospheric transmittances are calculated with the fast radiative transfer model RTTOV based on the cloud top height observed by SEVIRI and the forecasted water vapour profiles from the Met Office Unified Model. The water vapour correction has the largest impact on the above-cloud aerosol retrieval. The impact of errors in the atmospheric correction has been evaluated by modulating the humidity profile for a case study. A positive bias of both the AOT and the COT is observed when the water vapour is overestimated, and vice versa. On average, an $18.5 \%$ bias on the AOT and a $5.5 \%$ bias on the COT are expected for a $10 \%$ error on the water vapour profile. Although a good accuracy is expected from the forecast model, this limitation should be kept in mind when utilizing or further developing SEVIRI products. In the companion paper, the humidity from the forecast will be compared against the dropsonde measurements from the CLARIFY-2017 campaign.

The choice of the aerosol model used to produce the LUT is also a key feature of the method. In situ measurements of aerosols above clouds have been performed off the coast of Ascension Island during the CLARIFY-2017 field campaign. An aerosol model optimized for the SEVIRI spectral bands has been obtained by analysing the vertical profiles of extinction and absorption from EXSCALABAR together with the size distribution from a PCASP. A bimodal lognormal distribution has shown to adequately reproduce the observations. A fine-mode radius of $0.12 \mu \mathrm{m}$ has been obtained, which is in good agreement with the biomass burning measured over the SEAO during SAFARI 2000 (Haywood et al., 2003). The refractive index has been evaluated at $1.51-0.029 i$. The corresponding SSA of 0.85 at $0.55 \mu \mathrm{m}$ is consistent with both in situ and remote-sensing observations of African biomass burning aerosols (Johnson et al., 2008; Sayer et al., 2014). In addition to the uncertainty associated with the estimation of the aerosol model, a seasonal dependence is expected in the biomass burning properties as well as modifications due to ageing processes during their transport over the SEAO. We have evaluated the impact of applying a single model assumption on both aerosol and cloud properties. Retrievals have been performed considering aerosol models with modified SSA and asymmetry factor $g$. It has been shown that the sensitivity of the retrieved cloud properties to the aerosol model assumption is small, with errors lower than $5.6 \%$ on 

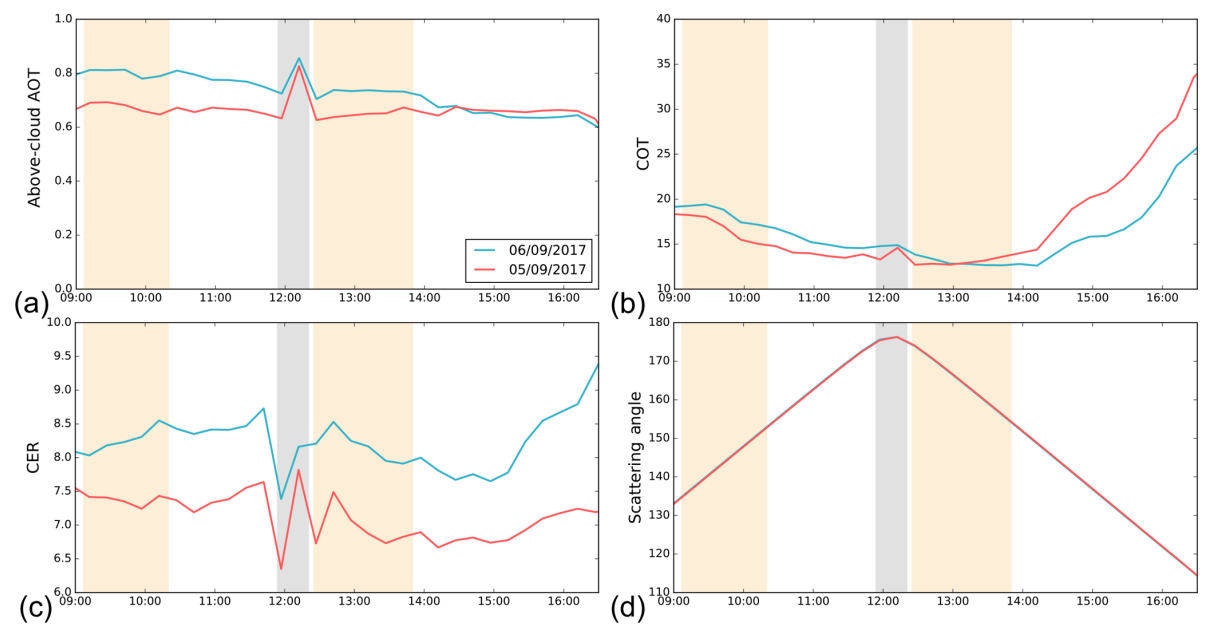

Figure 13. Time series (UTC) of the above-cloud AOT (a), COT (b), CER (c) and scattering angle (d) averaged between 20 and $10^{\circ} \mathrm{S}$ and 5 and $15^{\circ} \mathrm{E}$ for 5 and 6 September 2017 . The grey area represents scattering angles larger than $175^{\circ}$ and the orange areas show the typical overpass times of MODIS Aqua and Terra over the region.

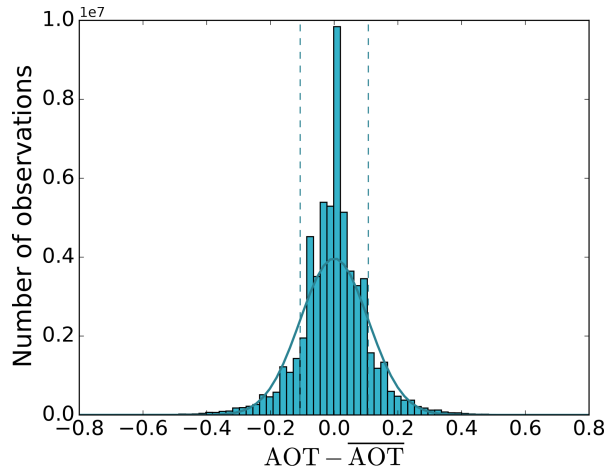

Figure 14. Histogram of the difference between AOT retrieved at $t=0$ and the running mean calculated between $t-15$ and $t+15 \mathrm{~min}$ from 1 to 12 September 2017. Observations within the glory region have been removed. Dashed lines represent the mean \pm the standard deviation.

the COT and $2.6 \%$ on the CER. As expected the impact of the assumed aerosol properties is much larger on the abovecloud AOT, with an uncertainty estimated at $40 \%$ before 15:00 UTC. This uncertainty is led by the sensitivity of the retrieval to the SSA. Because the method relies on the impact of the aerosol absorption on the light reflected by the clouds, the perturbation of the SSA has primarily an impact on the scattering contribution of the AOT. Therefore, a better accuracy is obtained on the retrieved AAOT, with biases generally lower than $17 \%$ before 15:00 UTC. After that time, an increase in the uncertainty on both the AOT and the AAOT has been observed, and users are advised to be careful when using the late afternoon aerosol product. For any satellite retrievals based on the colour-ratio technique, aerosol properties, including the SSA, have to be assumed and the same order of magnitude can be expected on the sensitivity of their
AOT. This analysis highlights the importance of a suitable constraint on the SSA.

Despite the wider channels and the narrower spectral range of SEVIRI, it has been demonstrated that the geostationary instrument has the potential to detect and quantify the absorbing aerosol plumes transported above the clouds of the SEAO. Except from observations within the glory backscattering for which the retrieval has shown to be unstable, a good consistency has been observed on the aerosol and cloud properties. The stability of the results during the day is promising for future uses of the SEVIRI algorithm. In the companion paper, the reliability of the retrieved aerosol and cloud properties will be further assessed by analysing the consistency with the MODIS retrievals and comparing with direct measurements from the CLARIFY-2017 field campaign. The potential of such a retrieval is obvious. The 15 min resolution will aid in tracking the fate of above-cloud biomass burning aerosol and will prove invaluable for assessing models of the emission, transport and deposition of biomass burning aerosol, with implications for accurate determination of the direct radiative effects of biomass burning aerosol at high temporal resolution.

Data availability. The data used for this study are available from the corresponding author, FP, upon reasonable request.

Author contributions. FP, PF and JMH developed the concept and the ideas for this paper. PF implemented the atmospheric correction scheme and FP the retrieval algorithm. CF, SJA, KS, MIC, NWD and JMH operated, calibrated and prepared the in situ measurements from EXSCALABAR and the PCASP. The reliability of the retrieved products was analysed throughout the development of the 
algorithm with the help of KGM and SEP. FP carried out the analysis and prepared the paper with contributions from all co-authors.

Competing interests. The authors declare that they have no conflict of interest.

Special issue statement. This article is part of the special issue "New observations and related modelling studies of the aerosolcloud-climate system in the Southeast Atlantic and southern Africa regions (ACP/AMT inter-journal SI)". It is not associated with a conference.

Acknowledgements. We thank the Natural Environment Research Council (NERC) and the Norwegian Research Council for their financial support. Airborne data were obtained using the BAe-146 Atmospheric Research Aircraft operated by Directflight Ltd. and managed by Facility for Airborne Atmospheric Measurements (FAAM), which is jointly supported by NERC and the Met Office. The authors acknowledge the dedicated work of FAAM and Directflight during the aircraft campaign. We thank the AERONET PIs, Paola Formenti, Derek Griffith, Brent Holben, Nichola Knox, Gillian Maggs-Kölling, Stuart Piketh, Carlos Ribeiro, Venkataram Sivakumar and Rick Wagener for their efforts in establishing and maintaining the Ascension Island, Bethlehem, Bonanza, DRAGON Henties, Durban UKZN, Elandsfontein, Etosha Pan, Gobabeb, Gorongosa, Henties Bay, HESS, Huambo, Inhaca, Joberg, Kaoma, Loskop Dam, Lubango, Maun Tower, Mongu, Mwinilunga, Namibe, Ndola, Paardefontein, Pietersburg, Possession Island, Potchefstroom, Pretoria CSIR-DPSS, Senanga, Sesheke, Skukuza, Solwezi, Swakopmund, Tsumkwe, Upington, Walvis Bay airport, Windhoek-NUST, Windpoort and Wits University sites.

Financial support. This research has been supported by the Natural Environment Research Council (NERC) via the CLARIFY project (grant no. NE/L013479/1) and the Research Council of Norway via the projects $\mathrm{AC} / \mathrm{BC}$ (grant no. 240372) and NetBC (grant no. 244141).

Review statement. This paper was edited by Nikolaos Mihalopoulos and reviewed by Ian Chang and one anonymous referee.

\section{References}

Aminou, D. M. A., Jacquet, B., and Pasternak, F.: Characteristics of the Meteosat Second Generation (MSG) radiometer/imager: SEVIRI, Proc. SPIE, 3221, 19-31, https://doi.org/10.1117/12.298084, 1997.

Brindley, H. and Ignatov, A.: Retrieval of mineral aerosol optical depth and size information from Meteosat Second Generation SEVIRI solar reflectance bands, Remote Sens. Environ., 102, 344-363, https://doi.org/10.1016/j.rse.2006.02.024, 2006.
Browell, E. V., Fenn, M. A., Butler, C. F., Grant, W. B., Clayton, M. B., Fishman, J., Bachmeier, A. S., Anderson, B. E., Gregory, G. L., Fuelberg, H. E., Bradshaw, J. D., Sandholm, S. T., Blake, D. R., Heikes, B. G., Sachse, G. W., Singh, H. B., and Talbot, R. W.: Ozone and aerosol distributions and air mass characteristics over the South Atlantic Basin during the burning season, J. Geophys. Res.-Atmos., 101, 24043-24068, https://doi.org/10.1029/95JD02536, 1996.

Brown, A., Milton, S., Cullen, M., Golding, B., Mitchell, J., and Shelly, A.: Unified Modeling and Prediction of Weather and Climate: A 25-Year Journey, B. Am. Meteorol. Soc., 93, 1865-1877, https://doi.org/10.1175/BAMS-D-12-00018.1, 2012.

Chang, I. and Christopher, S. A.: Identifying Absorbing Aerosols Above Clouds From the Spinning Enhanced Visible and Infrared Imager Coupled With NASA A-Train Multiple Sensors, IEEE T. Geosci. Remote, 54, 3163-3173, https://doi.org/10.1109/TGRS.2015.2513015, 2016.

Clayton, A. M., Lorenc, A. C., and Barker, D. M.: Operational implementation of a hybrid ensemble/4D-Var global data assimilation system at the Met Office, Q. J. Roy. Meteor. Soc., 139, 1445-1461, https://doi.org/10.1002/qj.2054, 2013.

Cotterell, M. I., Orr-Ewing, A. J., Szpek, K., Haywood, J. M., and Langridge, J. M.: The impact of bath gas composition on the calibration of photoacoustic spectrometers with ozone at discrete visible wavelengths spanning the Chappuis band, Atmos. Meas. Tech., 12, 2371-2385, https://doi.org/10.5194/amt12-2371-2019, 2019.

Davies, N. W., Cotterell, M. I., Fox, C., Szpek, K., Haywood, J. M., and Langridge, J. M.: On the accuracy of aerosol photoacoustic spectrometer calibrations using absorption by ozone, Atmos. Meas. Tech., 11, 2313-2324, https://doi.org/10.5194/amt11-2313-2018, 2018.

Davies, N. W., Fox, C., Szpek, K., Cotterell, M. I., Taylor, J. W., Allan, J. D., Williams, P. I., Trembath, J., Haywood, J. M., and Langridge, J. M.: Evaluating biases in filter-based aerosol absorption measurements using photoacoustic spectroscopy, Atmos. Meas. Tech., 12, 3417-3434, https://doi.org/10.5194/amt12-3417-2019, 2019.

de Graaf, M., Tilstra, L. G., Wang, P., and Stammes, P.: Retrieval of the aerosol direct radiative effect over clouds from spaceborne spectrometry, J. Geophys. Res.-Atmos., 117, D07207, https://doi.org/10.1029/2011JD017160, 2012.

de Haan, J. F., Bosma, P., and Hovenier, J.: The adding method for multiple scattering calculations of polarized light, Astron. Astrophys., 183, 371-391, 1987.

Eck, T. F., Holben, B. N., Ward, D. E., Mukelabai, M. M., Dubovik, O., Smirnov, A., Schafer, J. S., Hsu, N. C., Piketh, S. J., Queface, A., Roux, J. L., Swap, R. J., and Slutsker, I.: Variability of biomass burning aerosol optical characteristics in southern Africa during the SAFARI 2000 dry season campaign and a comparison of single scattering albedo estimates from radiometric measurements, J. Geophys. Res.-Atmos., 108, 8477, https://doi.org/10.1029/2002JD002321, 2003.

Edwards, J. M. and Slingo, A.: Studies with a flexible new radiation code. I: Choosing a configuration for a largescale model, Q. J. Roy. Meteor. Soc., 122, 689-719, https://doi.org/10.1002/qj.49712253107, 1996.

Francis, P. N., Hocking, J. A., and Saunders, R. W.: Improved diagnosis of low-level cloud from MSG SEVIRI data for assimila- 
tion into Met Office limited area models, in: Proceedings of the 2008 EUMETSAT Meteorological Satellite Conference, Darmstadt, 2008.

Gordon, H., Field, P. R., Abel, S. J., Dalvi, M., Grosvenor, D. P., Hill, A. A., Johnson, B. T., Miltenberger, A. K., Yoshioka, M., and Carslaw, K. S.: Large simulated radiative effects of smoke in the south-east Atlantic, Atmos. Chem. Phys., 18, 15261-15289, https://doi.org/10.5194/acp-18-15261-2018, 2018.

Hamann, U., Walther, A., Baum, B., Bennartz, R., Bugliaro, L., Derrien, M., Francis, P. N., Heidinger, A., Joro, S., Kniffka, A., Le Gléau, H., Lockhoff, M., Lutz, H.-J., Meirink, J. F., Minnis, P., Palikonda, R., Roebeling, R., Thoss, A., Platnick, S., Watts, P., and Wind, G.: Remote sensing of cloud top pressure/height from SEVIRI: analysis of ten current retrieval algorithms, Atmos. Meas. Tech., 7, 2839-2867, https://doi.org/10.5194/amt-72839-2014, 2014.

Haywood, J. M., Osborne, S. R., Francis, P. N., Keil, A., Formenti, P., Andreae, M. O., and Kaye, P. H.: The mean physical and optical properties of regional haze dominated by biomass burning aerosol measured from the C-130 aircraft during SAFARI 2000, J. Geophys. Res.-Atmos., 108, 8473, https://doi.org/10.1029/2002JD002226, 2003.

Haywood, J. M., Osborne, S. R., and Abel, S. J.: The effect of overlying absorbing aerosol layers on remote sensing retrievals of cloud effective radius and cloud optical depth, Q. J. Roy. Meteor. Soc., 130, 779-800, https://doi.org/10.1256/qj.03.100, 2004.

Herman, M., Deuzé, J.-L., Marchand, A., Roger, B., and Lallart, P.: Aerosol remote sensing from POLDER/ADEOS over the ocean: Improved retrieval using a nonspherical particle model, J. Geophys. Res.-Atmos., 110, https://doi.org/10.1029/2004JD004798, 2005.

Hocking, J., Rayer, P., Rundle, D., Saunders, R., Matricardi, M., Geer, A., Brunel, P., and Vidot, J.: RTTOV v11 Users Guide, NWP-SAF Report, Met Office, Exeter, UK, 2014.

Iwabuchi, H. and Suzuki, T.: Fast and accurate radiance calculations using truncation approximation for anisotropic scattering phase functions, J. Quant. Spectrosc. Ra., 110, 1926-1939, https://doi.org/10.1016/j.jqsrt.2009.04.006, 2009.

Jethva, H., Torres, O., Remer, L. A., and Bhartia, P. K.: A Color Ratio Method for Simultaneous Retrieval of Aerosol and Cloud Optical Thickness of Above-Cloud Absorbing Aerosols From Passive Sensors: Application to MODIS Measurements, IEEE T. Geosci. Remote, 51, 3862-3870, https://doi.org/10.1109/TGRS.2012.2230008, 2013.

Johnson, B. T., Osborne, S. R., Haywood, J. M., and Harrison, M. A. J.: Aircraft measurements of biomass burning aerosol over West Africa during DABEX, J. Geophys. Res.-Atmos., 113, D00C06, https://doi.org/10.1029/2007JD009451, 2008.

Keil, A. and Haywood, J. M.: Solar radiative forcing by biomass burning aerosol particles during SAFARI 2000: A case study based on measured aerosol and cloud properties, J. Geophys. Res.-Atmos., 108, 8467, https://doi.org/10.1029/2002JD002315, 2003.

Koppmann, R., von Czapiewski, K., and Reid, J. S.: A review of biomass burning emissions, Part I: gaseous emissions of carbon monoxide, methane, volatile organic compounds, and nitrogen containing compounds, Atmos. Chem. Phys. Discuss., 5, 1045510516, https://doi.org/10.5194/acpd-5-10455-2005, 2005.
Koren, I., Kaufman, Y. J., Remer, L. A., and Martins, J. V.: Measurement of the Effect of Amazon Smoke on Inhibition of Cloud Formation, Science, 303, 1342-1345, https://doi.org/10.1126/science.1089424, 2004.

Levy, R. C., Remer, L. A., Tanre, D., Mattoo, S., and Kaufman, Y. J.: Algorithm for remote sensing of tropospheric aerosol over dark targets from MODIS: Collections 005 and 051: Revision 2, Feb 2009, MODIS algorithm theoretical basis document, 2009.

Lu, Z., Liu, X., Zhang, Z., Zhao, C., Meyer, K., Rajapakshe, C., Wu, C., Yang, Z., and Penner, J. E.: Biomass smoke from southern Africa can significantly enhance the brightness of stratocumulus over the southeastern Atlantic Ocean, P. Natl. Acad. Sci. USA, 115, 2924-2929, https://doi.org/10.1073/pnas.1713703115, 2018.

Magi, B. I. and Hobbs, P. V.: Effects of humidity on aerosols in southern Africa during the biomass burning season, J. Geophys. Res.-Atmos., 108, 8495, https://doi.org/10.1029/2002JD002144, 2003.

Manners, J.: Socrates technical guide suite of community radiative transfer codes based on edwards and slingo, in: Tech. Rep., Met Office, FitzRoy Rd, Exeter EX1 3PB, 2015.

Martins, J. V., Hobbs, P. V., Weiss, R. E., and Artaxo, P., Sphericity and morphology of smoke particles from biomass burning in Brazil, J. Geophys. Res., 103, 32051- 32057, https://doi.org/10.1029/98JD01153, 1998.

Matricardi, M.: The generation of RTTOV regression coefficients for IASI and AIRS using a new profile training set and a new lineby-line database, European Centre for Medium-Range Weather Forecasts, 47 pp., 2008.

Matricardi, M., Chevallier, F., Kelly, G., and Thépaut, J.-N.: An improved general fast radiative transfer model for the assimilation of radiance observations, Q. J. Roy. Meteor. Soc., 130, 153-173, https://doi.org/10.1256/qj.02.181, 2004.

Mayer, B., Schröder, M., Preusker, R., and Schüller, L.: Remote sensing of water cloud droplet size distributions using the backscatter glory: a case study, Atmos. Chem. Phys., 4, 12551263, https://doi.org/10.5194/acp-4-1255-2004, 2004.

McClatchey, R. A., Fenn, R. W., Selby, J. A., Volz, F., and Garing, J.: Optical properties of the atmosphere, Tech. Rep., Air Force Cambridge Research Labs Hanscom AFB MA, 113 pp., 1972.

Meyer, K., Platnick, S., and Zhang, Z.: Simultaneously inferring above-cloud absorbing aerosol optical thickness and underlying liquid phase cloud optical and microphysical properties using MODIS, J. Geophys. Res.-Atmos., 120, 5524-5547, https://doi.org/10.1002/2015JD023128, 2015.

Min, M. and Zhang, Z.: On the influence of cloud fraction diurnal cycle and sub-grid cloud optical thickness variability on all-sky direct aerosol radiative forcing, J. Quant. Spectrosc. Ra., 142, 25-36, https://doi.org/10.1016/j.jqsrt.2014.03.014, 2014.

Nakajima, T. and King, M. D.: Determination of the Optical Thickness and Effective Particle Radius of Clouds from Reflected Solar Radiation Measurements. Part I: Theory, J. Atmos. Sci., 47, 1878-1893, https://doi.org/10.1175/15200469(1990)047<1878:DOTOTA >2.0.CO;2, 1990.

Nakajima, T. and Tanaka, M.: Algorithms for radiative intensity calculations in moderately thick atmospheres using a truncation approximation, J. Quant. Spectrosc. Ra., 40, 51-69, https://doi.org/10.1016/0022-4073(88)90031-3, 1988. 
Peers, F., Waquet, F., Cornet, C., Dubuisson, P., Ducos, F., Goloub, P., Szczap, F., Tanré, D., and Thieuleux, F.: Absorption of aerosols above clouds from POLDER/PARASOL measurements and estimation of their direct radiative effect, Atmos. Chem. Phys., 15, 4179-4196, https://doi.org/10.5194/acp15-4179-2015, 2015.

Peers, F., Bellouin, N., Waquet, F., Ducos, F., Goloub, P., Mollard, J., Myhre, G., Skeie, R. B., Takemura, T., Tanré, D., Thieuleux, F., and Zhang, K.: Comparison of aerosol optical properties above clouds between POLDER and AeroCom models over the South East Atlantic Ocean during the fire season, Geophys. Res. Lett., 43, 3991-4000, https://doi.org/10.1002/2016GL068222, 2016.

Platnick, S.: Vertical photon transport in cloud remote sensing problems, J. Geophys. Res., 105, 22919-22935, 2000.

Rosenberg, P. D., Dean, A. R., Williams, P. I., Dorsey, J. R., Minikin, A., Pickering, M. A., and Petzold, A.: Particle sizing calibration with refractive index correction for light scattering optical particle counters and impacts upon PCASP and CDP data collected during the Fennec campaign, Atmos. Meas. Tech., 5, 1147-1163, https://doi.org/10.5194/amt-5-1147-2012, 2012.

Rosenfeld, D.: Suppression of Rain and Snow by Urban and Industrial Air Pollution, Science, 287, 1793-1796, https://doi.org/10.1126/science.287.5459.1793, 2000.

Sayer, A. M., Hsu, N. C., Eck, T. F., Smirnov, A., and Holben, B. N.: AERONET-based models of smoke-dominated aerosol near source regions and transported over oceans, and implications for satellite retrievals of aerosol optical depth, Atmos. Chem. Phys., 14, 11493-11523, https://doi.org/10.5194/acp-14-114932014, 2014.

Szczodrak, M., Austin, P. H. and Krummel, P. B.: Variability of Optical Depth and Effective Radius in Marine Stratocumulus Clouds, J. Atmos. Sci., 58, 2912-2926, https://doi.org/10.1175/15200469(2001)058<2912:VOODAE>2.0.CO;2, 2001.

Thieuleux, F., Moulin, C., Bréon, F. M., Maignan, F., Poitou, J., and Tanré, D.: Remote sensing of aerosols over the oceans using MSG/SEVIRI imagery, Ann. Geophys., 23, 3561-3568, https://doi.org/10.5194/angeo-23-3561-2005, 2005.

Torres, O., Jethva, H., and Bhartia, P. K.: Retrieval of Aerosol Optical Depth above Clouds from OMI Observations: Sensitivity Analysis and Case Studies, J. Atmos. Sci., 69, 1037-1053, https://doi.org/10.1175/JAS-D-11-0130.1, 2012.
Twomey, S.: Pollution and the planetary albedo, Atmos. Environ., 8, 1251-1256, https://doi.org/10.1016/0004-6981(74)90004-3, 1974.

Waquet, F., Cornet, C., Deuzé, J.-L., Dubovik, O., Ducos, F., Goloub, P., Herman, M., Lapyonok, T., Labonnote, L. C., Riedi, J., Tanré, D., Thieuleux, F., and Vanbauce, C.: Retrieval of aerosol microphysical and optical properties above liquid clouds from POLDER/PARASOL polarization measurements, Atmos. Meas. Tech., 6, 991-1016, https://doi.org/10.5194/amt-6-9912013, 2013a.

Waquet, F., Peers, F., Ducos, F., Goloub, P., Platnick, S., Riedi, J., Tanré, D., and Thieuleux, F.: Global analysis of aerosol properties above clouds, Geophys. Res. Lett., 40, 5809-5814, https://doi.org/10.1002/2013GL057482, 2013b.

Watts, P., Mutlow, C., Baran, A., and Zavody, A.: Study on cloud properties derived from Meteosat Second Generation observations, EUMETSAT ITT, no 97/181, 344 pp., 1998.

Wilcox, E. M.: Stratocumulus cloud thickening beneath layers of absorbing smoke aerosol, Atmos. Chem. Phys., 10, 1176911777, https://doi.org/10.5194/acp-10-11769-2010, 2010.

Wilcox, E. M.: Direct and semi-direct radiative forcing of smoke aerosols over clouds, Atmos. Chem. Phys., 12, 139-149, https://doi.org/10.5194/acp-12-139-2012, 2012.

Wiscombe, W.: The Delta-M method: Rapid yet accurate radiative flux calculations for strongly asymmetric phase functions, J. Atmos. Sci., 34, 1408-1422, 1977.

Zuidema, P., Redemann, J., Haywood, J., Wood, R., Piketh, S., Hipondoka, M., and Formenti, P.: Smoke and Clouds above the Southeast Atlantic: Upcoming Field Campaigns Probe Absorbing Aerosol's Impact on Climate, B. Am. Meteorol. Soc., 97, 1131-1135, https://doi.org/10.1175/BAMS-D-15-00082.1, 2016.

Zuidema, P., Sedlacek III, A. J., Flynn, C., Springston, S., Delgadillo, R., Zhang, J., Aiken, A. C., Koontz, A., and Muradyan, P.: The Ascension Island Boundary Layer in the Remote Southeast Atlantic is Often Smoky, Geophys. Res. Lett., 45, 44564465, https://doi.org/10.1002/2017GL076926, 2018. 